UNIVERSIDADE DE SÃO PAULO

FACULDADE DE MEDICINA DE RIBEIRÃO PRETO

MESTRADO PROFISSIONAL EM HEMOTERAPIA E BIOTECNOLOGIA

ÊMILE CRISTINA SOUZA BETTARELLO

\title{
PRODUÇÃO E AVALIAÇÃO DE REAGENTES ERITROCITÁRIOS IMUNOHEMATOLÓGICOS EM BANCOS DE SANGUE
}

Ribeirão Preto 


\section{ÊMILE CRISTINA SOUZA BETTARELLO}

\section{PRODUÇÃO E AVALIAÇÃO DE REAGENTES ERITROCITÁRIOS IMUNOHEMATOLÓGICOS EM BANCOS DE SANGUE}

Versão Original

Dissertação apresentada à Faculdade de Medicina de Ribeirão Preto da Universidade de São Paulo para a obtenção do título de Mestre em Ciências.

Área de concentração: Hemoterapia e Medicina Transfusional. Orientadora: Prof ${ }^{\mathrm{a}}$. Dra. FABIOLA ATTIE DE CASTRO.

Ribeirão Preto 


\section{AUTORIZO A REPRODUÇÃO E DIVULGAÇÃO TOTAL OU PARCIAL DESTE TRABALHO, POR QUALQUER MEIO CONVENCIONAL OU ELETRÔNICO, PARA FINS DE ESTUDO E PESQUISA, DESDE QUE CITADA A FONTE.}

Catalogação da publicação

Serviço de Biblioteca e Documentação

Hemocentro de Ribeirão Preto - Universidade de São Paulo

\section{Bettarello, Êmile Cristina Souza}

Produção e avaliação de reagentes eritrocitários imunohematológicos em bancos de sangue / Êmile Cristina Souza Bettarello; orientadora Prof ${ }^{-}$Dra Fabiola Attie de Castro. - Ribeirão Preto, 2018.

56f. : il.

Dissertação de mestrado apresentada à Faculdade de Medicina de Ribeirão

Preto, Universidade de São Paulo. Área de concentração: Hemoterapia e Medicina Transfusional

1. Sistema sanguíneo. 2. Anticorpos. 3. Antígenos. 4. Fenótipo. 5. Aloimunização.

6. Reagentes eritrocitários. 7. Transfusão. 
Nome: BETTARELLO, Êmile Cristina Souza

Título: PRODUÇÃO E AVALIAÇÃO DE REAGENTES ERITROCITÁRIOS IMUNOHEMATOLÓGICOS EM BANCOS DE SANGUE

Dissertação apresentada à Faculdade de Medicina de Ribeirão Preto da Universidade de São Paulo para a obtenção do título de Mestre em Ciências.

Aprovado em:

Banca examinadora

Prof. (a)Dr.(a):

Instituição:

Julgamento:

Prof. (a)Dr.(a):

Instituição:

Julgamento:

Prof. (a)Dr.(a):

Instituição:

Julgamento: 
Dedico este trabalho a todos os profissionais que trabalham na área da saúde, que buscam pela qualidade dos serviços prestados e bem estar dos pacientes. 


\section{AGRADECIMENTOS}

A Deus por ter me dado saúde e força para superar as dificuldades e realizar o sonho de fazer mestrado.

Aos meus filhos, meus pais e meus avós, pela compreensão e paciência quando da minha ausência em diversos momentos e encorajamento constante.

À Dra. Flávia Leite, médica responsável do laboratório de Imunohematologia do Hemocentro de Ribeirão Preto, pelo incentivo, motivação e apoio fundamental.

À minha orientadora Dra. Fabíola Attie pela confiança, convicção e paciência no decurso do projeto.

A toda a equipe do Hemocentro de Ribeirão Preto, pela dedicação na organização de todo o Programa de Mestrado, em especial a equipe do Laboratório de Imunohematologia pelo apoio e paciência.

Agradecimento especial à amiga, parceira e supervisora Nicole Pezzi que nunca me deixou desistir frente a todas as adversidades neste projeto e a qual sem sua ajuda não teria concluído essa etapa.

À Dra. Eugênia M. Amorim Ubiali, por suas prontas e sinceras contribuições no aprimoramento da minha formação profissional e pela confiança em mim depositada.

À Rodrigo Spessoto pela motivação e confiança que em mim depositou, sempre fornecendo base para meu crescimento profissional.

Enfim, agradeço a todos que participaram, em diversos e inúmeros momentos da minha vida, tornando eu a pessoa que sou e que se traduz, em parte, nesta contribuição científico-acadêmica e profissional. 


\section{RESUMO}

Bettarello, Êmile Cristina Souza. PROduÇÃo E AVALIAÇÃo dE REAGENTES ERITROCITÁRIOS IMUNOHEMATOLÓGICOS EM BANCOS DE SANGUE. 2018. $56 f$.

Dissertação (Mestrado em Hemoterapia e Medicina Transfusional). Faculdade de Medicina de Ribeirão Preto, Universidade de São Paulo, Ribeirão Preto, 2018.

A rotina pré transfusional em Imunohematologia demanda a utilização de reagentes eritrocitários para detecção de anticorpos naturais e irregulares, objetivando a obtenção de maior segurança do evento transfusional para o paciente por minimizar os riscos de reações indesejadas. Para qualificação, padronização e liberação dos reagentes utilizados em imunohematologia, a seleção do perfil fenotípico dos reagentes eritrocitários é crucial. Desta forma, este trabalho demonstra a possibilidade do uso de doações de concentrado de hemácias para produção de reagentes eritrocitários pelos Hemocentros que detêm a matéria prima e o conhecimento para escolha do perfil de doadores correto. Os resultados sugerem que os hemocentros possuem a capacidade de confeccionar "kits" empregados para a realização da prova de tipagem sanguínea reversa e detecção de anticorpos irregulares, provas pré-transfusionais. As principais vantagens da produção dos reagentes pelos hemocentros seriam o baixo custo e a regionalização dos antígenos eritrocitários escolhidos, o que conduziria a maior eficácia na identificação de anticorpos irregulares na população de doadores de hemocomponentes.

Palavras-chave: Sistema sanguíneo. Anticorpos. Antígenos. Imunofenótipo. Aloimunização. Reagentes eritrocitários. Transfusão. 


\begin{abstract}
Bettarello, Êmile Cristina Souza. PRODUCTION AND EVALUATION OF IMMUNOHEMATOLOGICAL ERYTHROCYTES REAGENTS IN BLOOD BANKS. 2018. $56 f$.

Dissertation (Master in Hemotherapy and Transfusion Medicine) - Medical School of Ribeirão Preto, University of São Paulo, Ribeirão Preto, 2018.
\end{abstract}

The pre-transfusion routine in Immunohematology requires the use of erythrocyte reagents for the detection of natural and irregular antibodies, aiming to obtain greater safety of the transfusion event for the patient by minimizing the risks of unwanted reactions. For qualification, standardization and release of the reagents used in immunohematology, the selection of the phenotypic profile of erythrocyte reagents is crucial. In this way, this work demonstrates the possibility of the use of donations of red blood cells for the production of erythrocyte reagents by Blood Banks that holds the raw material and the knowledge to choose the correct donor profile. The results suggest that blood banks have the ability to make kits used to perform the reverse blood typing test and the detection of irregular antibodies, pre-transfusion tests. The main advantages of the production of the reagents by the blood banks would be the low cost and the regionalization of the erythrocyte antigens chosen, which would lead to greater efficacy in the identification of irregular antibodies in the donor population of blood components.

Keywords: Blood system. Antibodies. Antigens. Phenotype. Aloimunization. Erythrocyte Reagents.Transfusion. 


\section{LISTA DE FIGURAS}

Figura 1. Aparelho de Agote. Adaptação de Eugênio de

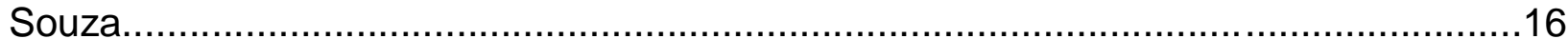

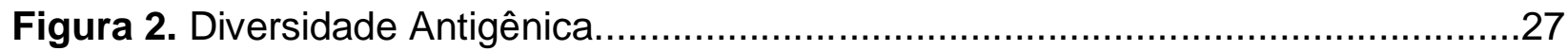

Figura 3. Avaliação imunohematológica pré-transfusional.........................................34

Figura 4. Resultados comparativos dos 16 lotes iniciais de triagem de anticorpos.

Figura 5. Resultado global para PAI testando hemácias comerciais e hemácias produzidas "in house"

Figura 6. Portaria de Consolidação Número 5 - Ministério da Saúde. Exames qualificatórios em doadores de sangue. Seção VI Dos Exames de Qualificação no Sangue do Doador (Origem: PRT MS/GM 158/2016, TíTULO II, CAPÍTULO I, Seção $\mathrm{VI})$.

Figura 7. Portaria de Consolidação Número 5 - Ministério da Saúde. Seção X Da Transfusão Sanguínea (Origem: PRT MS/GM 158/2016, TíTULO II, CAPÍTULO I, Seção X). 


\section{LISTA DE QUADROS}

Quadro 1. Sistemas de grupos sanguíneos com os mais importantes antígenos.........22

Quadro 2. Exemplos de terminologia de antígenos e fenótipos nas nomenclaturas

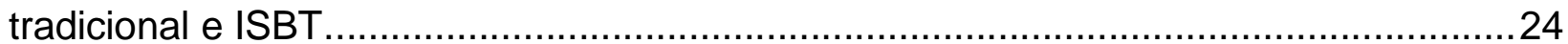

Quadro 3. Diagrama de perfil antigênico de reagentes eritrocitários utilizados na triagem da PAI. Colunas em destaque indicam antígenos destruídos por enzimas.......30 


\section{LISTA DE TABELAS}

Tabela 1. Importância Transfusional dos Anticorpos Irregulares. .32

Tabela 2. Interpretação do grau de intensidade das reações de aglutinação pelo

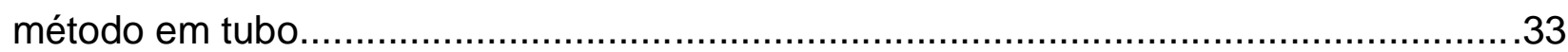

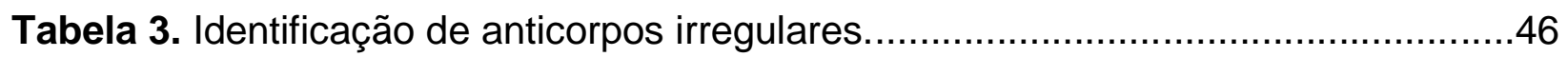

Tabela 4. Resultados obtidos na identificação de anticorpos irregulares......................47 


\section{SUMÁRIO}

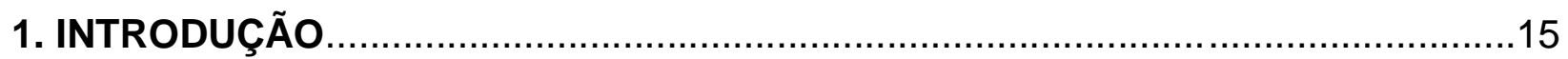

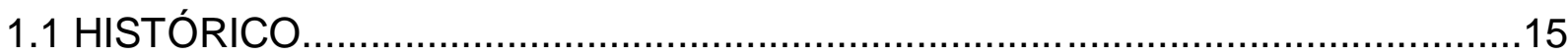

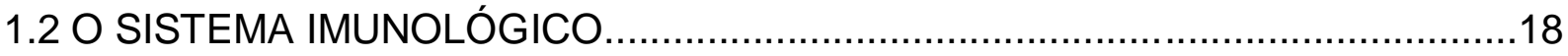

1.3 ANTÍGENO, ANTICORPO E A INTERAÇÃO ANTÍGENO-ANTICORPO.............20

1.4 GRUPOS SANGUÍNEOS: DEFINIÇÃO E NOMENCLATURA............................22

1.5 IMPORTÂNCIA DOS GRUPOS SANGUÍNEOS PARA A PRÁTICA

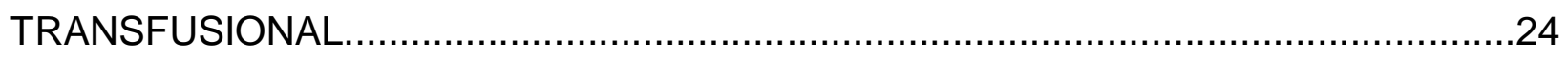

1.6 EXAMES REALIZADOS NO SETOR DE IMUNO-HEMATOLOGIA DOS

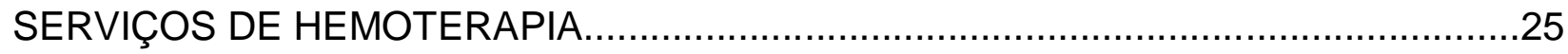

1.6.1 Tipagem sanguínea direta e reversa................................................25

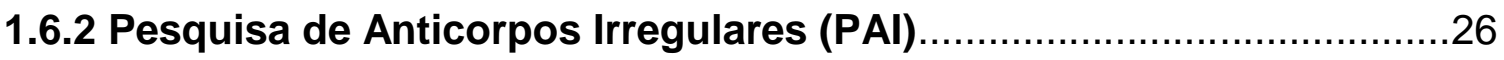

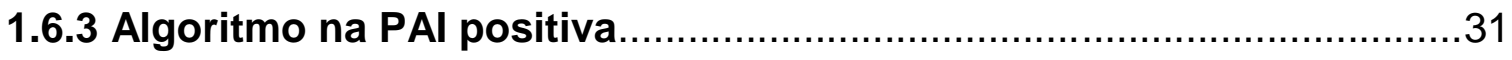

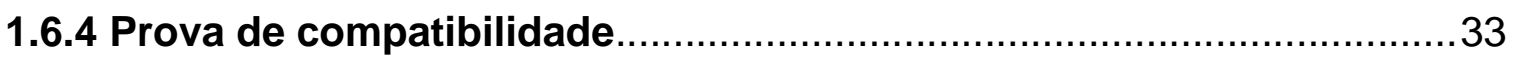

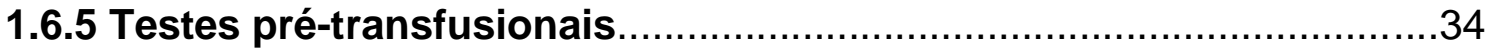

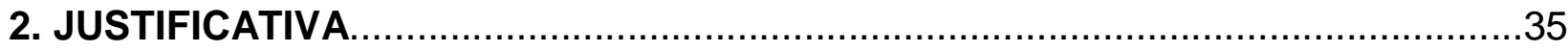

3. OBJETIVOS

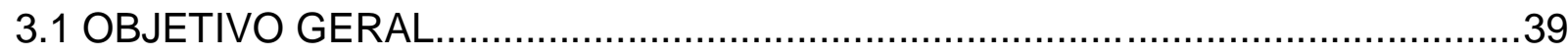

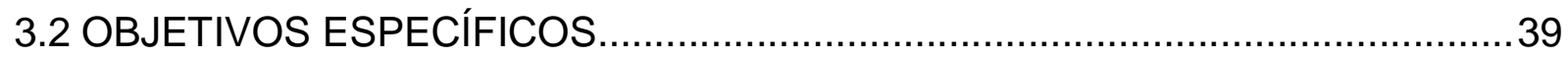

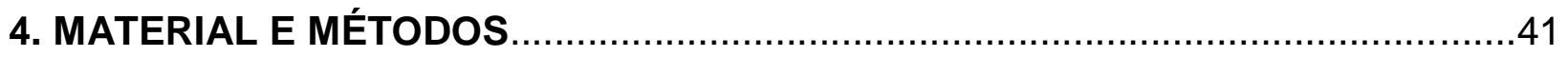

4.1 SELEÇÃO DAS MATÉRIA-PRIMA PARA A PRODUÇÃO DOS REAGENTES

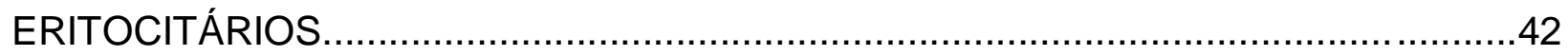

4.2 PRODUÇÃO DOS REAGENTES ERITROCITÁRIOS E CONTROLES...............42

4.3 VALIDAÇÃO DOS REAGENTES ERITROCITÁRIOS .....................................43

4.3.1 Pesquisa de anticorpos irregulares (PAI) e tipagem confirmatória reversa para investigação de grupo sanguíneo $A B O$ 
6. DISCUSSÃO

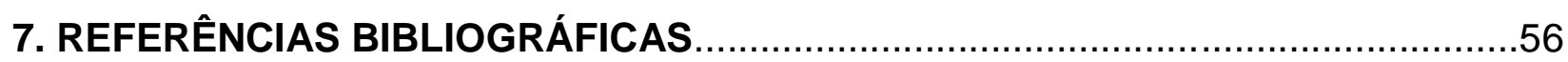

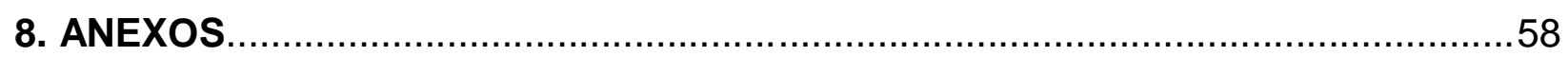


Introdução 


\section{INTRODUÇÃO}

\subsection{HISTÓRICO}

O percurso para obtenção de uma técnica de transfusão eficiente, segura e não complicada foi bastante difícil, mas houve grande progresso(HARMENING, 2006).

Segundo Carvalho (1995), os primeiros relatos sobre transfusão de sangue animal-para-animal e animal-para-homem datam dentre os anos de 1656 a 1668, em trabalhos resgatados na biblioteca de Londres referentes aos primeiros passos da hemoterapia, com Christopher Wren e Robert Boyle e a administração de ópio e várias outras substâncias em um cão.

No passado, como conta a médica e pesquisadora Maria Teresita Bendicho, alguns médicos utilizavam sangue de outros animais quando o paciente precisava de transfusão, o que causou diversos problemas e mortes(HARMENING, 2006). Posteriormente, os médicos passaram a fazer transfusão de sangue só entre seres humanos, porém, as doenças e as mortes continuaram acontecendo. Isso porque, como não se conheciam os grupos sanguíneos, opaciente que recebia sangue diferente do delee reagia (reação transfusional).

Dessa forma, pesquisadores decidiram estudar por que isso ocorria, e foi assim que Karl Landsteiner chegou à descoberta dos grupos sanguíneos.Aproximadamente 10 anos após os relatos de problemas com as transfusões de sangue, este procedimento para humanos foi proibido. Tanto na França quanto na Inglaterra, coube a James Blundell,150 anos mais tarde, recuperar a transfusão como método terapêutico e estabeleceu as bases da moderna hemoterapia.

O caminho para as transfusões bem-sucedidas foi repleto de muitos insucessos, mas, a fascinação física, espiritual e emocional pelo sangue foi primordial (HARMENING, 2006).

A transfusão de sangue no mundo teve dois períodos: o empírico (dos primeiros relatos até 1900) e o científico (1900 em diante), depois das descobertas de Karl Landsteiner. 
Karl Landsteiner descobriu os grupos sanguíneos $\mathrm{ABO}$, explicando as sérias reações que acontecem com os resultados das transfusões incompatíveis(BORDIN; LANGHI JÚNIOR; COVAS, 2007).

Logo após, Edward Lindemann descreveu dispositivos apropriados para executar as transfusões, e primeiramente foram usadas múltiplas seringas e cânula especial para perfurar a veia, técnica esta conhecida como veia para veia. Posteriormente, surgiu o aparato seringa-válvula para a transfusão doador para paciente, projetado por Unger.

Em 1900,na fase científica,foi realizada a primeira transfusão de sangue no Brasil, realizada pelo professor de clínica médica Garcez Froés, o qual transfundiu $129 \mathrm{ml}$ de sangue do doador para a paciente por meio de um aparelho chamado Agote (Aparelho de Eugenio de Souza) (Figura 1). No ano de 1916, Isaura Leitão defendeu a tese sobre "Transfusão Sanguínea" relatando este caso e mais três outros.

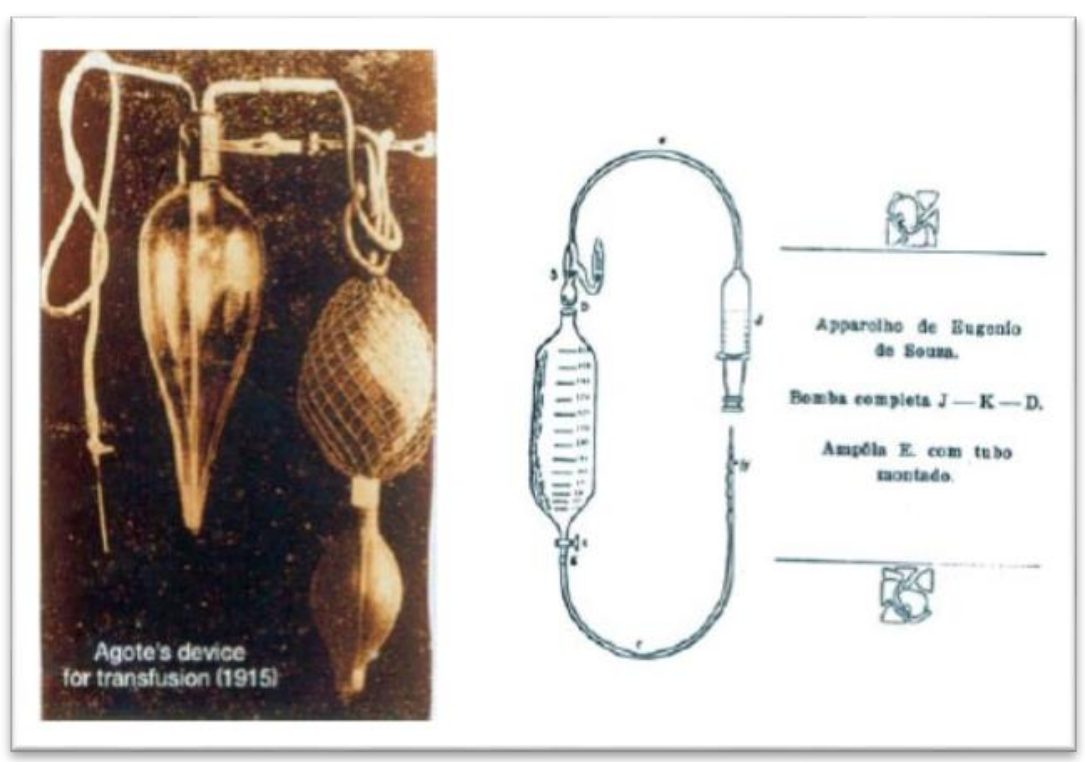

Figura 1. Aparelho de Agote. Adaptação de Eugênio de Souza (JUNQUEIRA, 2005). 
Ainda neste período, foram feitos relatos de preservação do sangue (HUSTIN, 1914), por meio da utilização do citrato de sódio como solução anticoagulante para transfusões (JUNQUEIRA et al., 2007; HARMENING, 2006).

O advento da Segunda Guerra Mundial estimulou a busca por métodos de conservação e preservação do sangue devido a demanda, com isso, em 1941, Charles Drew estabeleceu um sistema de bancos de sangue na cruz vermelha americana, um projeto modelo.Paralelamente na Inglaterra (1943), foi introduzida afórmula do conservante ácido-citrato-dextrose (ACD), resultando em diversas publicações sobre a conservação do sangue. Depois de muitos trabalhos, a rede de bancos de sangue foi estabelecida em hospitais das grandes cidades nos Estados Unidos no ano de 1947, todos por doação voluntária (HARMENING, 2006).

Historicamente, o papel dos bancos de sangue estava predominantemente relacionado a testes destinados a detecção de antígenos de grupo sanguíneo e anticorpos.Com a expansão, foi necessário maior conhecimento da resposta imune global na avaliação, desempenho e resolução de problemas de testes de banco de sangue, ocorrendo assim o desenvolvimento de procedimentos e protocolos cada vez mais complexos (LEWIS E SHARON, apud HARMENING, 2006).

De acordo com Junqueira et al. (2007), após estes fatos, surgiram serviços especializados com organização simples, commédico hemoterapeuta e doadores universais (tipo O), selecionados e examinados.

No Brasil, A hemoterapia brasileira foi iniciada com Nestor Rosa Martins em 1933, com a criação do Serviço de Transfusão de Sangue (STS), no Rio de Janeiro. Em 1937,foram criadas novas filiais em Juiz de Fora, Salvador, e outras de curta duração. O marco da hemoterapia brasileira aconteceu ao mesmo tempo no Rio de Janeiro e emSão Paulo, em meados de 1942, com a inauguração do primeiro banco de sangue no Instituto Fernandes Figueira (RJ), visando a obtenção de sangue para hospitais, atendendo ao esforço de guerra e com Osvaldo Mellone, com a criação do Banco de Sangue do Hospital das Clínicas (SP), posteriormente reconhecido como "Banco de Sangue São Paulo" (Junqueira et al. 2007).

A partir da criação do Banco de Sangue do Distrito Federal (1944), foi promulgada a Lei no 1075 em 27 de março de 1950, que dispôs sobre a doação voluntária de sangue, sendo fundada assim a Associação de Doadores Voluntários do Brasil. De 1964 a 1979, a hemoterapia no Brasil passou a ter normatizações e legislações,o que conduziua uma política consistente no setor. 
Em 1988, com a constituição-artigo 199, ficou estabelecida a assistência à saúde de forma livre da iniciativa privada, e em seu parágrafo 4 diz que a lei disporá sobre condições e requisitos que facilitem a remoção de órgãos, tecidos e substâncias humanas para fins de transplantes, pesquisa e tratamento, bem como a coleta, processamento e transfusão de sangue e seus componentes, vedado todo tipo de comercialização.

Em 2002, Sérgio Aroucainstituiu a remuneração dos serviços por meio da cobertura de custos de processamento, acrescentando mais credibilidade aos serviços de Hemoterapia no Brasil.

Hoje, a transfusão tornou-se mais eficiente e segura devido ao aperfeiçoamento metodológico e científico da Hemoterapia e Hematologia aplicada aos bancos de sangue.

\subsection{O SISTEMA IMUNOLÓGICO}

A palavra imunidade deriva da palavra latina immunitas, que se traduz na proteção dos senadores romanos contra processos legais que tinham durante o seu mandato (ABBAS, 2005). A história traduz imunidade como o fator de proteção às doenças, em especial as infecciosas (ABBAS, 2005).

O sistema imune é composto por células e moléculas que tem como objetivo combater as substâncias estranhas (ABBAS, 2005). A função fisiológica do sistema imunológico é a defesa contra microrganismos infecciosos, embora até mesmo substâncias estranhas não infecciosas possam desencadear resposta imunológica (ABBAS, 2005).

A defesa contra microrganismos é mediada pelas reações da imunidade natural e adaptativa. A imunidade natural, conhecida também como inata ou nativa compreende os mecanismos de defesa celulares e bioquímicos que se ativam previamente ao quadro de infecção. Os mecanismos efetores da imunidade natural fornecem a defesa inicial contra infecções, visto que a resposta imune adaptativa se desenvolve posteriormente e consiste na resposta específica ao antígeno (ABBAS, 2005).

A imunidade protetora contra microrganismos é mediada pelas reações iniciais da imunidade natural e pelas respostas posteriores da imunidade adquirida. 
A imunidade natural é estimulada por estruturas comuns a grupos de microrganismos. A imunidade adquirida é específica para diferentes antígenos microbianos e não microbianos, sendo acentuada por repetidas exposições ao antígeno (memória imunológica) (ABBAS, 2005).

A imunidade pode ainda ser caracterizada como adquirida por meio da resposta a um antígeno (imunidade ativa) ou conferida pela transferência de anticorpos ou de células de uma pessoa imunizada (imunidade passiva) (ABBAS, 2005).

A resposta imunológica adquirida é iniciada pelo reconhecimento de antígenos estranhos por linfócitos específicos. Os linfócitos proliferam e se diferenciam em células efetoras, cuja função é eliminar o antígeno, e células de memória, que apresentam uma resposta acentuada nas exposições posteriores ao antígeno (ABBAS, 2005).

A fase efetora da imunidade adquirida requer a participação de vários mecanismos de defesa, incluindo o sistema do complemento e as células fagocitárias, que também participam da imunidade natural. A imunidade adquirida acentua os mecanismos de defesa da imunidade natural (ABBAS, 2005).

A Imunidade pode ser ainda dividida didaticamente em humoral e celular. A imunidade humoral é mediada pelos linfócitos $B$, sistema complemento, moléculas solúveis e anticorpos, que atuam principalmente na defesa contra os microrganismos extracelulares. A imunidade celular é mediada principalmente pelos linfócitos $\mathrm{T}$ e seus produtos, tais como as citocinas, sendo importante para a defesa contra microrganismos intracelulares (ABBAS, 2005).

A primeira demonstração experimental da imunidade humoral foi fornecida por Emil von Behring e Shibasaburo Kitasato em 1890. Eles relataramque o plasma de animais curados da difteria quando transferidos para animais sadios, tornava-os imunes à infecção pela difteria. Os componentes ativos do plasma foram chamados de antitoxinas, pois neutralizavam os efeitos da toxina diftérica.

No início dos anos 1900, Karl Landsteiner e outros investigadores demonstraram que, além de antitoxinas, substâncias antibacterianas podiam induzir respostas imunológicas humorais. Desses estudos, surgiu o termo anticorpos para designar as proteínas plasmáticas que mediavam a imunidade humoral. As substâncias que se ligam aos anticorpos e geram a sua produção foram chamadas de antígenos (ABBAS, 2003). 
Os anticorpos se ligam especificamente a seus respectivos antígenos (alvos) e recrutam outras células para destruí-los (Inbal Sela Culang, 2013).

\subsection{ANTÍGENO, ANTICORPO E A INTERAÇÃO ANTÍGENO-ANTICORPO}

Antígenos são classicamente definidos como substâncias reconhecidas pelo organismo como "não próprias" e que podem estimular a formação de anticorpos. Mais amplamente, podem ser definidos como qualquer substância capaz de interagir especificamente com o anticorpo ou receptor de células T (GIRELLO, 2016).

Os antígenos devem apresentar a imunogenicidade (capacidade de estimular a produção de anticorpos) e a antigenicidade (capacidade de ligar aos anticorpos). (GIRELLO, 2016)

A habilidade de estimular a resposta imune depende da natureza da substância, de sua complexidade estrutural e do modo de imunização (dose e presença de adjuvantes), além das características de cada indivíduo (genética, idade, gênero, etc...) (Girello, 2016).

Anticorpos são produzidos com a função principal de neutralizar e eliminar o antígeno que estimulou sua produção. Esse processo de eliminação é feito de diversas formas, mediante fixação do complemento, opsonização, reação anafilática (desgranulação de mastócitos), neutralização da substância e aglutinação. A função efetora dos anticorpos é desencadeada com a ligação destes com 0 antígeno (GIRELLO, 2016).

Os antígenos de grupos sanguíneos são definidos por anticorpos, geralmente aloanticorpos produzidos por indivíduos que não possuem 0 antígeno correspondente. Alguns anticorpos de grupos sanguíneos, como o anti-A e o Anti-B, estão presentes no plasma de todos os indivíduos, cujos glóbulos vermelhos não apresentam o antígeno correspondente. No entanto, a maioria dos anticorpos de grupos sanguíneos são formados em resposta aos antígenos presentes nas hemácias como resultado de transfusão ou gestação.

Alguns anticorpos causam a destruição imunológica das hemácias transfundidas que apresentam o antígeno correspondente, o que pode resultar numa reação transfusional hemolítica imediata ou tardia. Por exemplo, os anticorpos maternos da classe lgG são capazes de atravessar a barreira placentária e causar 
destruição imune das hemácias fetais ou inibir a maturação das células eritróides causando doença hemolítica do feto e do recém-nascido (DHFRN) (CASTILHO, 2015).

Os antígenos de grupos sanguíneos são determinantes antigênicos presentes na superfície das hemácias e que podem induzir uma resposta imune. Muitos destes antígenos já se encontram classificados nos 36 sistemas de grupos sanguíneos definidos pela Sociedade Internacional de Transfusão de Sangue (ISBT). Os antígenos desses sistemas são codificados por alelos (formas alternativas de um gene), por um único gene (a maioria dos sistemas de grupos sanguíneos), por um conjunto de genes estreitamente ligados e homólogos (três genes para o sistema MNS e dois para o sistema $\mathrm{CH} / \mathrm{RG}$ ), ou exigem a interação de produtos codificados por genes em cromossomos diferentes. (CASTILHO, Lilian, 2015).

Comparada a resposta imune a microrganismos, antígenos de grupos sanguíneos são considerados fracos imunógenos (SCHONEWILLE, 2008).Em uma reação transfusional, acredita-se que o processo ocorra de modo semelhante à imunização gerada por antígenos infeciosos. Assim sendo, ocorre o reconhecimento do antígeno de grupo sanguíneo como não próprio pelas células, os linfócitos são ativados no sangue periférico e, posteriormente, os anticorpos são produzidos. A ativação de células imunes determina a resposta não somente humoral, como também celular (WALKER et al, 1989). O aparecimento de anticorpos contra antígenos eritrocitários pode, habitualmente, ser detectado de três a quatro meses após a exposição antigênica, sendo o menor período de tempo compreendido de quatro semanas no caso de anti-D (LOZANO \&CID, 2003).

Para a detecção da aloimunização, é necessário que seja evidenciado o anticorpo no soro do paciente sob análise. Entretanto, em algumas situações, há falhas nessa detecção, como no caso da pesquisa de anticorpos ser realizada em estágio inicial, no qual o anticorpo encontra-se, usualmente, em título indetectável ou, em fase tardia, na qual o título encontra-se reduzido após longo período sem o estímulo antigênico.Outras condições quem podem acarretar em não detecção da presença de aloanticorpos são falhas no método e baixa afinidade do anticorpo (WALKER et al, 1989).

Os mecanismos efetores da resposta imune contra os antígenos eritrocitários são estudados pela imunohematologia. 


\subsection{GRUPOS SANGUÍNEOS: DEFINIÇÃO E NOMENCLATURA}

O termo grupo sanguíneo refere-se a um conjunto de antígenos com características semelhantes. Em 1900, Karl Landsteiner descobriu o primeiro sistema de grupos sanguíneos, o sistema $\mathrm{ABO}$. Com o aumento das pesquisas na área, novos antígenos foram descobertos e agrupados em outros sistemas (Girello, 2016).

Mais tarde, Decastello e Sturli descobriram mais um grupo sanguíneo: o AB. Além da classificação em $A, B, O$ e $A B$ existe outro grupo sanguíneo, muito imunogênico, classificado como Rh. O RhD foi descoberto por Karl Landsteiner em 1940. A partir desta descoberta, os grupos sanguíneos passaram a ser classificados como positivo ou negativo, ou seja, o sangue do tipo B pode ser B negativo ou $B$ positivo. $O$ fator $R$ h recebeu esse nome pois sua descoberta foi feita a partir de um macaco da espécie Rhesus.

A International Society of Blood Transfusion (ISBT), um grupo de trabalho com participantes de vários países, definiu a classificação e nomenclatura internacional para os antígenos de grupos sanguíneos. Essa classificação está baseada em princípios genéticos e basicamente divide os antígenos em quatro grandes famílias: os sistemas, as coleções e duas outras séries conhecidas como 700 e 901 (<ibgrl.blood.co.uk>) (Quadro 1).

Quadro 1. Sistemas de grupos sanguíneos com os mais importantes antígenos.

\begin{tabular}{|c|c|c|c|c|c|c|c|c|c|c|c|}
\hline \multirow{2}{*}{ Sistemas } & \multicolumn{11}{|c|}{ Antígenos } \\
\hline & 1 & 2 & 3 & 4 & 5 & 6 & 7 & 8 & 9 & 10 & Total \\
\hline $001 \mathrm{ABO}$ & A & B & $A B$ & $A_{1}$ & & & & & & & \\
\hline 002 MNS & $M$ & $\mathrm{~N}$ & $S$ & $S$ & $U$ & $\mathrm{He}$ & $\mathrm{Mi}^{\mathrm{a}}$ & $M^{c}$ & Vw & Mur & 46 \\
\hline $003 P$ & $P_{1}$ & $\ldots$ & $\mathrm{P}^{\mathrm{k}}$ & NOR & & & & & & & \\
\hline 004 RH & $\mathrm{D}$ & C & $E$ & C & $E$ & $f$ & $\mathrm{Ce}$ & $\mathrm{C}^{\mathrm{w}}$ & $C^{x}$ & V & 57 \\
\hline $005 \mathrm{LU}$ & $\mathrm{Lu}^{\mathrm{a}}$ & $\mathrm{Lu}^{\mathrm{b}}$ & Lu3 & Lu4 & Lu5 & Lu6 & Lu7 & Lu8 & Lu9 & $\ldots$ & 21 \\
\hline $006 \mathrm{KEL}$ & K & K & $K p^{a}$ & $K p^{b}$ & $\mathrm{Ku}$ & $J^{a}$ & $\mathrm{JS}^{\mathrm{b}}$ & $\ldots$ & $\ldots$ & $\mathrm{Ul}^{\mathrm{a}}$ & 34 \\
\hline 007 LE & $\operatorname{Le}^{a}$ & $\mathrm{Le}^{\mathrm{b}}$ & $\mathrm{Le}^{\mathrm{ab}}$ & $\mathrm{Le}^{\mathrm{bH}}$ & $\mathrm{ALe}^{\mathrm{a}}$ & $\mathrm{BLe}^{\mathrm{b}}$ & & & & & \\
\hline $008 \mathrm{FY}$ & $F y^{a}$ & $\mathrm{Fy}^{\mathrm{b}}$ & Fy3 & $\ldots$ & Fy5 & Fy6 & & & & & \\
\hline $009 \mathrm{JK}$ & $\mathrm{Jk}^{\mathrm{a}}$ & $\mathrm{Jk}^{\mathrm{b}}$ & Jk3 & & & & & & & & \\
\hline $010 \mathrm{DI}$ & $\mathrm{Di}^{\mathrm{a}}$ & $\mathrm{Di}^{\mathrm{b}}$ & $W r^{a}$ & $W r^{b}$ & $W d^{a}$ & $\mathrm{Rb}^{\mathrm{a}}$ & WARR & ELO & $\mathrm{Wu}$ & Bpa & 21 \\
\hline
\end{tabular}


Continuação. Quadro 1. Sistemas de grupos sanguíneos com os mais importantes antígenos.

\begin{tabular}{|c|c|c|c|c|c|c|c|c|c|c|c|}
\hline \multirow[b]{2}{*}{ Sistemas } & \multicolumn{11}{|c|}{ Antígenos } \\
\hline & 1 & 2 & & 3 & 5 & 6 & 7 & 8 & 9 & 10 & Total \\
\hline $011 \mathrm{YT}$ & $Y^{a}{ }^{a}$ & $Y t^{b}$ & & & & & & & & & \\
\hline 012 XG & $\mathrm{Xg}^{\mathrm{a}}$ & CD99 & & & & & & & & & \\
\hline 013 SC & Sc1 & Sc2 & Sc3 & $\mathrm{Rd}$ & STAR & SCER & SCAN & & & & \\
\hline 014 DO & $\mathrm{Do}^{\mathrm{a}}$ & $\mathrm{Do}^{\mathrm{b}}$ & $G y^{a}$ & Hy & $\mathrm{JO}^{\mathrm{a}}$ & DOYA & DOMR & DOLG & DOLC & DODE & \\
\hline $015 \mathrm{CO}$ & $\mathrm{Co}^{\mathrm{a}}$ & $\mathrm{Co}^{\mathrm{b}}$ & Co3 & Co4 & & & & & & & \\
\hline 016 LW & & & & & $\mathrm{Lw}^{\mathrm{a}}$ & $L^{a}{ }^{a b}$ & $\mathrm{Lw}^{\mathrm{b}}$ & & & & \\
\hline $\begin{array}{l}017 \\
\mathrm{CH} / \mathrm{RG}\end{array}$ & Ch1 & Ch2 & Ch3 & Ch4 & Ch5 & Ch6 & WH & & & & \\
\hline $018 \mathrm{H}$ & $\mathrm{H}$ & & & & & & & & & & \\
\hline $019 \mathrm{XK}$ & Kx & & & & & & & & & & \\
\hline $020 \mathrm{GE}$ & $\mathrm{Ge} 2$ & Ge3 & Ge4 & $\mathrm{Wb}$ & $\mathrm{Ls}^{\mathrm{a}}$ & $A n^{a}$ & $\mathrm{Dh}^{\mathrm{a}}$ & GEIS & GEPL & GEAT & \\
\hline $\begin{array}{l}021 \\
\text { CROM }\end{array}$ & $\mathrm{Cr}^{\mathrm{a}}$ & $\mathrm{Tc}^{\mathrm{a}}$ & $T c^{b}$ & $\mathrm{Tc}^{\mathrm{c}}$ & $D r^{a}$ & $E s^{a}$ & IFC & WES $^{a}$ & WES $^{b}$ & UMC & 15 \\
\hline 022 KN & $\mathrm{Kn}^{\mathrm{a}}$ & $\mathrm{Kn}^{\mathrm{b}}$ & $\mathrm{McC}^{\mathrm{a}}$ & Sl1 & $Y^{a}$ & $\mathrm{McC}^{\mathrm{b}}$ & $\mathrm{S} 12$ & $\mathrm{~S} 13$ & KCAM & & \\
\hline 023 IN & $\ln ^{a}$ & $\ln ^{b}$ & INFI & INJA & & & & & & & \\
\hline 024 OK & $\mathrm{OK}^{\mathrm{a}}$ & OKGV & OKVM & & & & & & & & \\
\hline $\begin{array}{l}025 \\
\text { RAPH }\end{array}$ & MER2 & & & & & & & & & & \\
\hline $026 \mathrm{JMH}$ & JMH & JMHK & JMHL & JMHG & JMHM & JMHQ & & & & & \\
\hline 027 I & I & & & & & & & & & & \\
\hline $\begin{array}{l}028 \\
\text { GLOB }\end{array}$ & $P$ & PX2 & & & & & & & & & \\
\hline 029 GIL & GIL & & & & & & & & & & \\
\hline $\begin{array}{l}030 \\
\text { RHAG }\end{array}$ & Duclos & $\mathrm{Oi}^{\mathrm{a}}$ & DLSK & RHAG4 & & & & & & & \\
\hline 31 & FORS & FORS & & & & & & & & & \\
\hline 32 & $J R$ & $\mathrm{Jr}^{\mathrm{a}}$ & & & & & & & & & \\
\hline 33 & LAN & Lan & & & & & & & & & \\
\hline 34 & VEL & Vel & & & & & & & & & \\
\hline 35 & CD59 & CD59.1 & & & & & & & & & \\
\hline 36 & AUG & AUG1 & AUG2 & & & & & & & & \\
\hline
\end{tabular}

Fonte: Autoria própria.

Os sistemas de grupos sanguíneos são constituídos por antígenos com características genéticas e bioquímicas semelhantes. Até o momento, foram descritos 36 sistemas de grupos sanguíneos. 
As coleções são conjuntos de antígenos com características sorológicas, bioquímicas e genéticas também semelhantes, porém, não relacionadas aos sistemas de grupos sanguíneos até então estabelecidos.

As séries de antígenos são formadas por estruturas antigênicas conhecidas do ponto de vista sorológico e agrupadas em dois grupos: antígenos de baixa frequência populacional, quando menos de $1 \%$ da população possui esses antígenos (denominada série 700) e antígenos de alta frequência, quando presente em mais de $90 \%$ da população (série 901 ).

Apesar da importância desta terminologia internacional definida pela ISBT, a nomenclatura tradicional ainda é muito utilizada em bancos de sangue. Neste caso, os antígenos foram nomeados utilizando-se a primeira letra do nome dos pacientes (em que os anticorpos foram identificados - exemplo Duffy) ou do nome do pesquisador. Os demais antígenos de um mesmo sistema foram identificados por letra sobrescrita como $\mathrm{Le}^{\mathrm{a}}$, $\mathrm{Le}^{\mathrm{b}}$, $\mathrm{Lu}^{\mathrm{a}}$, $\mathrm{Jk}^{\mathrm{a}}$, $\mathrm{Jk}^{\mathrm{b}}$ e mais recentemente sequências numéricas (Ex.: Fy3, Jk3). O quadro 2 mostra alguns exemplos das duas nomenclaturas (tradicional e ISBT).

Quadro 2. Exemplos de terminologia de antígenos e fenótipos nas nomenclaturas tradicional e ISBT.

\begin{tabular}{|c|c|c|c|}
\hline Sistema & \multicolumn{2}{|c|}{ Nomenclatura Tradicional } & Nomenclatura ISBT \\
\hline \multirow{2}{*}{ Kell } & & $\mathrm{K}, \mathrm{k}, \mathrm{Js}^{\mathrm{a}}, \mathrm{Js}^{\mathrm{b}}$ & $\begin{array}{c}\text { KELL1, KELL2, KELL6, } \\
\text { Antígenos }\end{array}$ \\
& Fenótipos & $\mathrm{K}-\mathrm{k}+, \mathrm{Js}(\mathrm{b}+)$ & $\mathrm{Kell}:-1,2,7$ \\
\hline & Antígenos & $\mathrm{Fy}^{\mathrm{a}}, \mathrm{Fy}$ & $\mathrm{Fy} 1, \mathrm{Fy} 2$ \\
\hline \multirow{2}{*}{ Duffy } & Fenótipos & $\mathrm{Fy}(\mathrm{a}+\mathrm{b}+)$ & $\mathrm{Fy}: 1,2$ \\
\hline
\end{tabular}

Fonte: Autoria própria.

\subsection{IMPORTÂNCIA DOS GRUPOS SANGUÍNEOS PARA A PRÁTICA TRANSFUSIONAL}

A imunohematologia é uma área essencialmente importante na prática transfusional, pois, garante a qualidade e a segurança imunológica de uma transfusão. Com a união de duas áreas importantes, a hematologia e a imunologia, é possível realizar um estudo teórico e laboratorial da interação dos eritrócitos e o sistema imunológico do paciente que irá receber a transfusão sanguínea (MINISTÉRIO DA SAÚDE, 2014). 
Os grupos sanguíneos mais utilizados para tipagem sanguínea são os grupos $A B O$ e $\mathrm{Rh}$, em decorrência da sua alta taxa de imunogenicidade, entretanto, é importante lembrar que existem outros sistemas sanguíneos que também tem a sua importância biológica: MNS, H, P, Lewis, Kell, Duffi, Kid, Lutheran, Diego (BONIFÁCIO ET AL, 2009).

Os anticorpos mais importantes no estudo hemoterápico são as aglutininas, proteínas presentes no plasma humano. Quando os tipos sanguíneos não são compatíveis, as aglutininas anti-A e anti-B são misturadas com os aglutinogênios $A$ ou $B$, fazendo com que ocorra um processo que forma grumos celulares, que consistem no processo de aglutinação (GYUTON ET AL, 2011).

O controle de qualidade na imuno-hematologia visa o monitoramento da prevenção de erros nos procedimentos pré-transfusionais. Todo procedimento médico que necessite de transfusões, só deve ser realizado mediante a realização prévia dos testes imunohematológicos, pois, a ocorrência de possíveis reações está ligada principalmente a falhas nos testes pré-transfusionais, como por exemplo, a existência de anticorpos não detectados na Pesquisa de Anticorpos Irregulares. O diagnóstico pré-transfusional é essencial para a prevenção de intercorrênciasdurante uma transfusão. Deve ser feita uma triagem clínica e laboratorial para garantir a segurança do sangue que irá ser transfundido. A triagem laboratorial consiste principalmente nos testes sorológicos dos doadores de sangue, e testes imuno-hematológicos em receptores de sangue.

Os testes realizados nas amostras de sangue têm o objetivo principal de classificar e verificar a compatibilidade sanguínea entre doador e receptor. Esses testes são realizados por meio das técnicas imuno-hematológicas e os principais testes exigidos são: Tipagem sanguínea $\mathrm{ABO} / \mathrm{Rh}$, Pesquisa de Anticorpos Irregulares (PAI) e testes de compatibilidade (MINISTÉRIO DA SAÚDE, 2014). A realização da tipagem sanguínea pode ser caracterizada pela classificação da presença ou ausência de antígenos $A$ e $B$ na membrana das hemácias. Dentreos testes pré-transfusionais, os testes que detectam os antígenos do Sistema $A B O / R h$ são os mais importantes devido à sua imunogenicidade (FREIRE, 2015).

\subsection{EXAMES REALIZADOS NO SETOR DE IMUNO-HEMATOLOGIA DOS SERVIÇOS DE HEMOTERAPIA}

\subsubsection{Tipagem sanguínea direta e reversa}

A determinação do grupo sanguíneo, no setor de imuno-hematologia dos hemocentros, deve ser realizada pordois testes: a tipagem direta e a tipagem 
reversa. A tipagem direta é realizada em amostras de sangue total, no qual é realizada a pesquisa dos antígenos presentes hemácias com reagentes contendo aglutininas (anticorpos) anti-A e anti-B. A pesquisa deve ser realizada em tubos contendo o sangue e os anticorpos. Após rápida centrifugação, observa-se a presença ou ausência de aglutinação. Se houver aglutinação, presume-se que ocorreu a reação do antígeno eritrocitário nas hemácias testadas com o anticorpo comercial e a reação é considerada positiva.

A tipagem reversa é realizada por meio da pesquisa dos anticorpos naturais, anti-A ou anti-B, em amostras de soro ou plasma, e são utilizados reagentes de antígenos conhecidos contendo hemácias tipo $A$ e hemácias tipo $B$ (MARTINS ET AL, 2009; LIU, 2012). Também deve ser realizada em tubos contendo o plasma e os antígenos A1 e B. Após rápida centrifugação, observa-se a presença ou ausência de aglutinação. Se houver aglutinação, presume-se que ocorreu a reação do antígeno eritrocitário comercial com o anticorpo presente no plasma testado.

\subsubsection{Pesquisa de Anticorpos Irregulares (PAI)}

Os anticorpos irregulares são imunoglobulinas produzidas durante os processos de aloimunização com hemácias, ou seja, são produzidos em resposta aos aloantígenos eritrocitários contidos em hemocomponentes transfundidos. $\mathrm{Na}$ rotina imuno-hematológica, aloanticorpos devem ser detectados e identificadosnos receptores para prevenção da reação transfusional (MINISTÉRIO DA SAÚDE, 2013).

O grande número de genes envolvidos na produção de proteínas eritrocitárias leva à formação de antígenos na superfície das hemácias dos indivíduos (diversidade antigênica), o que acarreta no risco de formação dos anticorpos irregulares (Figura 2). 


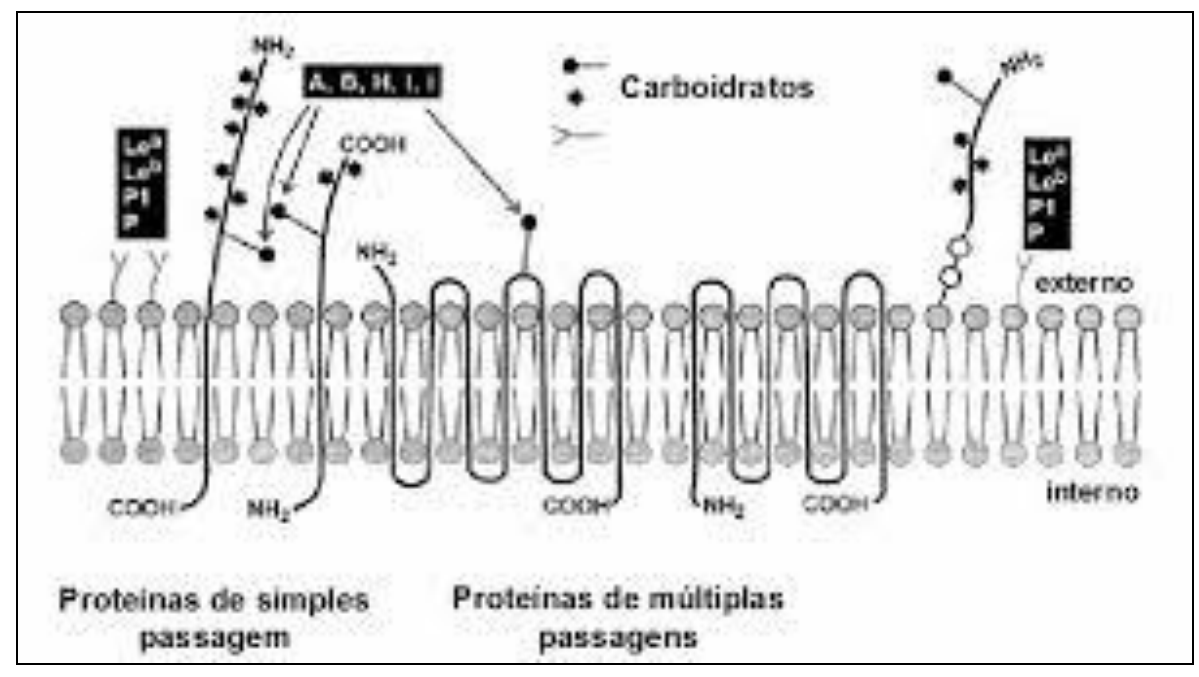

Figura 2. Diversidade Antigênica (REID, 2004).

Os anticorpos irregulares podem ocorrer em aproximadamente $0,3 \%$ a 2,0\% da população em geral. O risco de aloimunização é de aproximadamente $1 \%$ por unidade transfundida. Em determinadas populações, porém, esse risco é maior, sendo estimado em:

- Politransfundidos: 9\%

- Falciformes: $36 \%$

- Talassêmicos: $10 \%$

Os anticorpos irregulares podem ser encontrados no soro/plasma dos indivíduos ou ligados à membrana eritrocitária.Ocorrem principalmente por sensibilização após transfusão, gestação, ou ainda, podem ser de ocorrência natural.

A pesquisa dos anticorpos irregulares tem como objetivo detectar os anticorpos anti-eritrocitários presentes no soro/plasma dos receptores de sangue, ou seja, dos indivíduos que receberão o hemocomponente. A pesquisa desses anticorpos é importante devido ao potencial dos anticorpos de causar reações hemolíticas. $O$ teste de antiglobulina humana indiereto (Coombs) deve ser realizado obrigatoriamente (MINISTÉRIO DA SAÚDE, 2014). Nos hemocentros, a PAI faz parte da rotina devido ao alto contingente de transfusões.

Os testes pré-transfusionais devem ser realizados para que a transfusão de hemocomponentes sejaum procedimento seguro. A transfusão, quando indicada adequadamente, proporcionanumerosos benefícios para o receptor, porém, há 0 
risco da ocorrência de reações transfusionais e transmissão de doenças infectocontagiosas.Neste contexto, cabe aos hemocentros torná-las seguras minimizando os potenciais riscos por meio da identificação adequada do paciente e da realização dos testes imuno-hematológicos e infecto-contagiosos no sangue do doador e receptor.

As reações transfusionais graves podem colocar a vida do paciente em risco e, portanto, todas as medidas devem ser tomadas para evitar sua ocorrência e, caso ocorra, sua causa deve ser determinada.

A reação hemolítica, caracterizada como uma reação transfusional grave, decorre da transfusão de concentrado de hemácias $A B O$ incompatível, ou de hemácias que possuem antígenos para os quais o receptor apresenta anticorpos irregulares. Neste caso, as hemácias transfundidas são destruídas pelos anticorpos do receptor, causando hemólise intravascular (GENOVEZ, 2010).

A pesquisa de anticorpos irregulares é obrigatória em pacientes e doadores de sangue. O teste deve ter a capacidade de detectar anticorpos circulantes, dirigidos contra antígenos eritrocitários, anticorpos estes que possuam importância clínica.(GIRELLO, 2016)

Anticorpos clinicamente significantes são aqueles capazes de se ligar à membrana eritrocitária na temperatura corpórea, reduzirem a sobrevida das hemácias circulantes e atravessarem a barreira placentária. Estes anticorpos reagem após a incubação a $37^{\circ} \mathrm{C}$ e são detectados pelo teste indireto da antiglobulina. Os anticorpos que reagem em temperaturas próximas de $37^{\circ} \mathrm{C}$ são chamados anticorpos quentes e os que reagem à temperatura ambiente (aproximadamente $22^{\circ} \mathrm{C}$ ) são os anticorpos frios. Alguns anticorpos possuem uma grande amplitude térmica e reagem tanto "a quente" como "a frio" (Ministério da Saúde, 2013).

O teste PAI caracteriza-se pela reação de reagentes eritrocitários de triagem com soro ou plasma de doadores e pacientes. Os reagentes utilizados na pesquisa de anticorpos antieritrocitários são compostos, no mínimo, de hemácias de dois fenótipos distintos. Estas hemácias devem ser fenotipadas para os principais antígenos eritrocitários, cujos anticorpos apresentam importância clínica: D, C, c, E, e, K, k, Fy $y^{\mathrm{a}}, \mathrm{Fy}^{\mathrm{b}}$, Jk $\mathrm{Jk}^{\mathrm{a}}, \mathrm{Jk}^{\mathrm{b}}$, Le ${ }^{\mathrm{a}}$, Leb, M, N, S, s e P. Alguns antígenos devem estar em homozigose em pelo menos um dos reagentes (C, c, E, e, Fya $\left., F^{b}, J^{a}, J k^{b}, S, ~ s\right)$. Denomina-se homozigose ou antígenos em dose dupla quando a herança de alelos 
idênticos determina uma maior expressão dos antígenos na membrana da hemácia. (HULT, 2005). Os reagentes de triagem da PAl, devem ser acompanhados por um diagrama que mostra o perfil antigênico das hemácias e permite, por meio da comparação com os resultados obtidos, a verificação da especificidade dos anticorpos irregulares presente (Quadro 3).

A adição de meios potencializadores de aglutinação na PAI aumenta a sensibilidade do teste permitindo a detecção de anticorpos da classe IgG. Na rotina imuno-hematológica, a PAI é realizada frequentemente com LISS (Low lonic Strength Saline)e/ou pelo PEG (polietilenoglicol). As hemácias também podem ser submetidas ao tratamento enzimático. A diminuição da força iônica do meio aumenta o grau de associação do anticorpo ao antígeno correspondente, reduzindo o tempo de incubação do teste de deteç̧ão de anticorpos. O PEG proporciona o deslocamento de moléculas de água do meio, permitindo maior concentração de anticorpos ao redor das hemácias em suspensão, o que favorece a aglutinação. (Ministério da Saúde, 2013)

A PAI deve ser realizada também com soro antiglobulina, o qual potencializa a reação antígeno-anticorpo e promove a visualização dos casos fracamente positivos (MINISTÉRIO DA SAÚDE, 2013). 
Quadro 3. Diagrama de perfil antigênico de reagentes eritrocitários utilizados na triagem da PAI. Colunas em destaque indicam antígenos destruídos por enzimas

\begin{tabular}{|c|c|c|c|c|c|c|c|c|c|c|c|c|c|c|c|c|c|c|c|c|c|c|c|c|}
\hline & $\mathbf{R h}$ & \multicolumn{5}{|c|}{$\mathbf{R h}$} & \multicolumn{4}{|c|}{ MNSs } & $\mathbf{P}$ & \multicolumn{2}{|c|}{ Lutheran } & \multicolumn{4}{|c|}{ Kell } & \multicolumn{2}{|c|}{ Lewis } & \multicolumn{2}{|c|}{ Duffy } & \multicolumn{2}{|c|}{ Kidd } & DI \\
\hline & Fenótipos & D & C & $E$ & $C$ & $E$ & $M$ & $\mathrm{~N}$ & S & S & $P_{1}$ & $L u^{a}$ & $\mathrm{Lu}^{\mathrm{b}}$ & $\mathrm{K}$ & $\mathrm{k}$ & $\mathrm{Kp}^{\mathrm{a}}$ & $K p^{b}$ & $\operatorname{Le}^{a}$ & $\operatorname{Le}^{b}$ & $F y^{a}$ & $\mathrm{Fy}^{\mathrm{b}}$ & $\mathrm{Jk}^{\mathrm{a}}$ & $\mathrm{Jk}^{\mathrm{b}}$ & $\mathrm{Di}^{\mathrm{a}}$ \\
\hline 1 & $R 1^{\mathrm{w}} \mathrm{R} 1$ & + & + & 0 & 0 & + & + & 0 & + & + & + & + & + & 0 & + & 0 & + & 0 & 0 & 0 & + & 0 & + & 0 \\
\hline 3 & $\mathbf{R r}$ & 0 & 0 & 0 & + & + & + & + & + & 0 & 0 & 0 & + & 0 & + & 0 & + & + & 0 & + & 0 & 0 & + & 0 \\
\hline
\end{tabular}

Fonte: Autoria própria. 
Quando a presença de anticorpo irregular em um soro for positiva na PAl, deve-se identificar a especificidade do anticorpo utilizando-se um "painel de hemácias" contendo de 10 a 20 reagentes eritrocitários com fenótipos distintos, porém, conhecidos. A identificação do anticorpo presente no soro do receptor permite a seleção adequada do concentrado de hemácias para a transfusão (Ministério da Saúde, 2013).

\subsubsection{Algoritmo na PAl positiva}

Quando detectamos a presença de anticorpos irregulares, o próximo passo é identificar a especificidade do (s) anticorpo (s), utilizando painel de hemácias contendo de 8 a 30 hemácias-teste do grupo $\mathrm{O}$ e fenótipos conhecidos nos sistemas imunogênicos, em concentrações variando de $0,8 \%$ a $5 \%$, de acordo com o método empregado. Recomenda-se, caso necessário, o uso de hemácia-teste de cordão umbilical ou hemácia-teste de adulto com fenótipo I-negativo. As hemácias do painel são testadas contra o soro ou plasma do indivíduo, utilizando-se as mesmas técnicas que apresentaram PAI positiva. É necessário confirmar a especificidade do anticorpo suspeito com pelo menos três hemácias negativas e positivas para o antígeno correspondente. Acrescentar ao painel um autocontrole (Ac), para detectar possíveis auto-anticorpos é necessário. O painel de hemácias vem acompanhado de um diagrama com o fenótipo dos antígenosconsiderados "mais importantes" em bancos de sangue.

- Uma vez identificado o anticorpo, deve-se determinar seu significado clínico avaliando:

- Temperatura de reação;

- Potência (grau de reatividade);

- Classe da imunoglobulina;

- $\quad$ Subclasse da lgG;

- Capacidade de ativação do complemento.

Geralmente, anticorpos clinicamente significativossão reativos a $37^{\circ} \mathrm{C}$ e/ou fase de AGH. Portanto, são anticorpos de classe $\lg G$ ou IgM com amplitude térmica (Tabela 1). 
Tabela 1. Importância Transfusional dos Anticorpos Irregulares

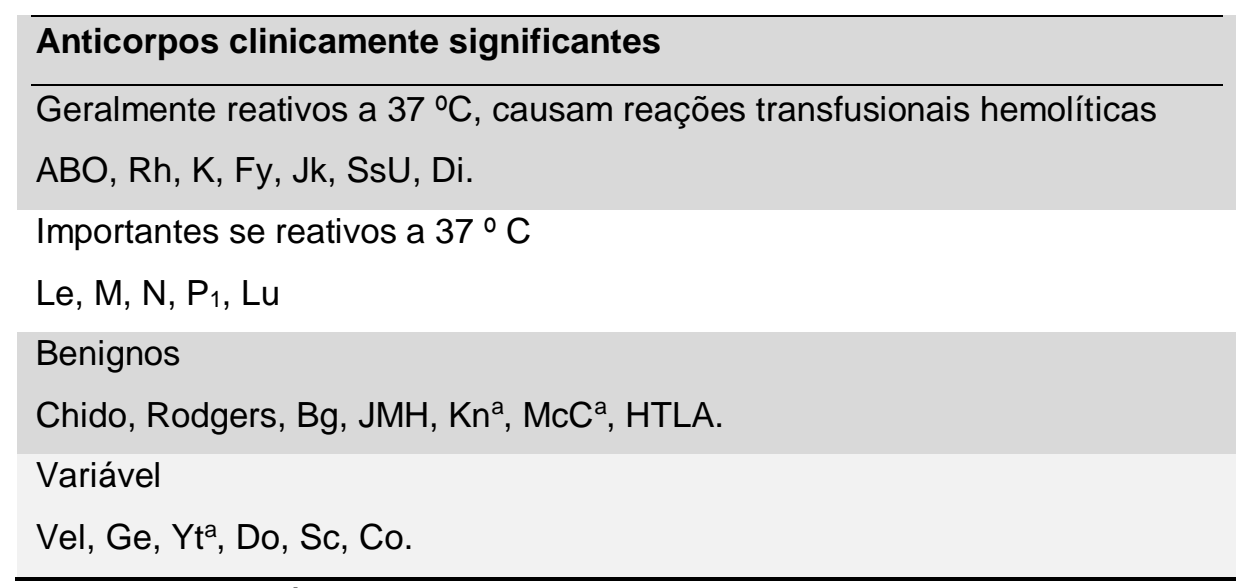

Fonte: Autoria própria.

Quando um anticorpo é identificado, é necessário realizar a contraprova para o antígeno correspondente, ou seja, deve-se proceder com a fenotipagem da hemácia do paciente para o antígeno que corresponde ao anticorpo identificado. Ex.: se detectarmos a existência de aloanticorpo de especificidade anti-K (K1), a hemácia do indivíduo deve ser fenótipo $\mathrm{K}$ negativo.

Quando o anticorpo for clinicamente significativo e houver necessidade de transfusão, deve-se selecionar sangue fenótipo-compatível para o receptor (fenotipagem da bolsa para o antígeno em questão). Ex.: no mesmo exemplo anterior apresentado, fenotipar a bolsa que apresentou prova de compatibilidade negativa para o antígeno K (K1).

Para melhor caracterização é recomendado, ainda, observar informações como idade, sexo, etnia, diagnóstico do paciente, histórico transfusional e registros anteriores em outros bancos de sangue já utilizados pelo paciente.

Cabe ressaltar que provas de compatibilidade negativas nem sempre significam ausência de anticorpo irregular na amostra-teste, pois, o título desse anticorpo pode ter decrescido e atingido níveis indetectáveis, por diminuição do estímulo antigênico, ou ainda, pelo teste empregado não apresentar sensibilidade suficiente para a detecção. Nesse primeiro caso, se houver novo estímulo antigênico, por meio de nova transfusão fenótipo-positiva, pode ocorrer resposta anamnéstica, com produção de altos títulos de anticorpos em período de 48 a 72 horas, e estímulo de reação transfusional de caráter imunológico. 
Portanto, é importante pesquisar a história transfusional de pacientes, se possível recuperando as informações sobre anticorpos preexistentes, e/ou até mesmo fornecendo bolsas fenotipadas, especialmente levando-se em conta os antígenos mais imunogênicos como os do sistema Rh (D, C, c, E, e), Kell (K1), Kidd $\left(\mathrm{Jk}^{\mathrm{a}}\right.$ e $\left.\mathrm{Jk}^{\mathrm{b}}\right)$ e Duffy $\left(\mathrm{Fy}^{\mathrm{a}}\right.$ e Fy $\left.\mathrm{Fy}^{\mathrm{b}}\right)$.

É importante a interpretação correta da intensidade de aglutinação que, tanto na detecção como na identificação de anticorpos, direciona e fornece dados significativos para a identificação. A seguir (Tabela 2) é apresentada uma sugestão de padronização de leitura de intensidade de aglutinação para testes realizados pelo método convencional (em tubo).

Tabela 2. Interpretação do grau de intensidade das reações de aglutinação pelo método em tubo

\begin{tabular}{ccc}
\hline $\begin{array}{c}\text { Grau de intensidade } \\
\text { da reação }\end{array}$ & Interpretação & Escore \\
\hline $\mathbf{4 +}$ & Botão sólido/nenhuma célula livre, fundo transparente & 12 \\
\hline $\mathbf{3 +}$ & Alguns aglutinados grandes mas separados, fundo límpido, & 10 \\
& Aglutinados maiores e menores, sobrenadante róseo & \\
\hline $\mathbf{2 +}$ & Aglutinados pequenos, mesmo tamanho; sobrenadante & 5 \\
$\mathbf{1 +}$ & avermelhado \\
W & & 3 \\
\hline
\end{tabular}

Fonte: Autoria própria.

\subsubsection{Prova de compatibilidade}

A prova de compatibilidade caracteriza-se pela reação da suspensão do concentrado de hemácias selecionado para a transfusão, com o soro do paciente. Assim como na PAI, deve a prova de compatibilidade deve ser realizada com a adição de substâncias potencializadoras (LISS e/ou PEG) e deve apresentar a fase com soro antiglobulina humana. É importante enfatizar que este teste demonstra apenas a presença de anticorpos irregulares dirigidos contra antígenos eritrocitários existentes no concentrado de hemácias selecionado para esta prova. Anticorpos com importância clínica no soro do receptor passam despercebidos se, por acaso, o 
concentrado de hemácia selecionado não tiver o antígeno correspondente. Dessa forma, a realização da PAl é fundamental para a segurança transfusional. (MINISTÉRIO DA SAÚDE, 2013).

\subsubsection{Testes Pré-Transfusionais}

A avaliação pré-transfusional para candidatos à transfusão é padronizada pelo Ministério da Saúde através de teste obrigatórios a serem realizados a cada nova transfusão. A figura 3 traz, resumidamente, os principais ensaios obrigatórios a cada solicitação de transfusão. Para execução dos testes pré-transfusionais há necessidade de utilização de reagentes contendo anticorpos conhecidos e reagentes eritrocitários com perfil fenotípico específico para a determinação de antígenos e anticorpos respectivamente. Os testes pré-transfusionais são fundamentais na determinação do perfil do receptor e consequentemente na escolha do perfil do doador. Portanto, é de extrema importância que os reagente utilizados sejam de alta qualidade e se enquadrem ao perfil populacional.

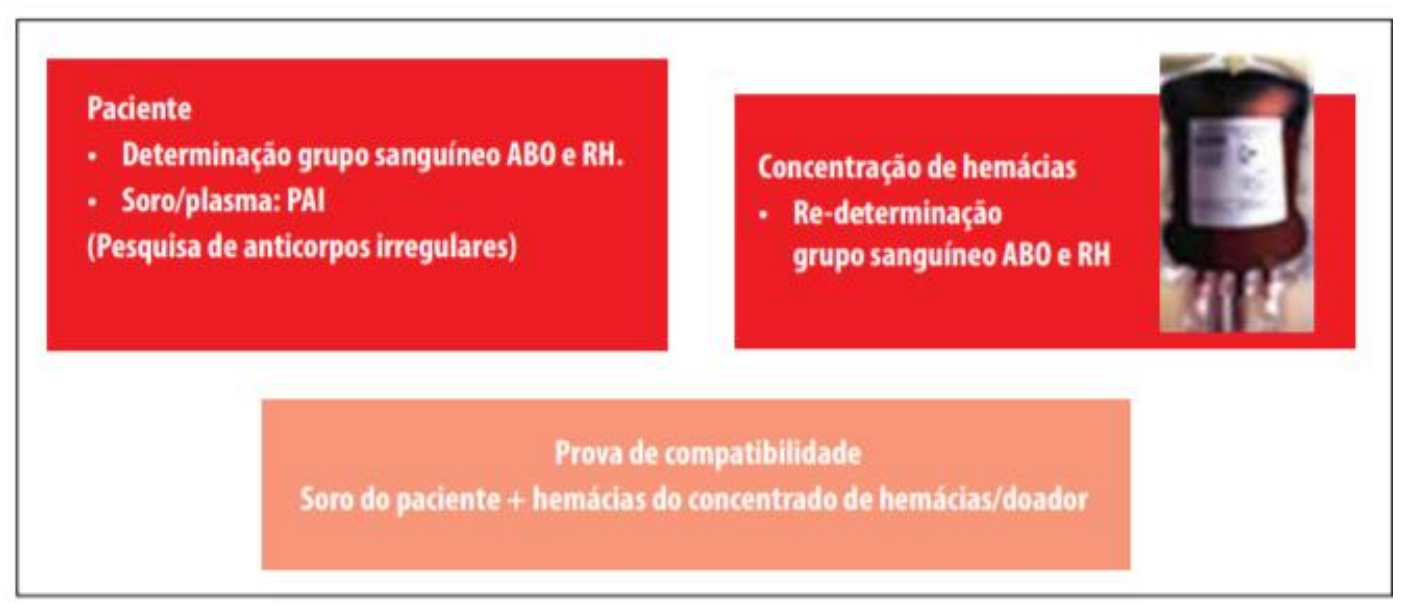

Figura 3. Avaliação imunohematológica pré-transfusional (MINISTÉRIO DA SAÚDE, 2013). 
Justificativa 


\section{JUSTIFICATIVA}

Com a publicação no Diário Oficial da União número 229 na seção 1 página 79 em 30 de novembro de 2010 da normativa do Ministério da Saúde: Portaria 1353 de 06 de junho de 2011 que implantou a recomendação da pesquisa de hemolisina para os doadores de sangue, especificamente plaquetas, como segue:

\section{Seção VI Dos Exames de Qualificação no Sangue do Doador}

Art. 63. O serviço de hemoterapia deverá realizar exames imunohematológicos para qualificação do sangue do doador, a fim de garantir a eficácia terapêutica e a segurança da futura doação.

§ 1ํ O serviço de hemoterapia deverá realizar a tipagem $A B O$, sobre o sangue doado, observando os seguintes critérios:

I - a tipagem $A B O$ deve ser realizada testando-se as hemácias com reagentes anti-A, anti-B e anti-AB; sendo que, no caso de serem usados antissoros monoclonais, a utilização do soro anti-AB não é obrigatória;

II - a tipagem reversa deve ser sempre realizada, testando-se o soro ou plasma de amostra da doação com suspensões de hemácias conhecidas $A 1$ e $B$ e, opcionalmente, A2 e O; e

III - nenhum hemocomponente deve ser rotulado e liberado para utilização até que qualquer discrepância entre a tipagem direta e reversa tenha sido resolvida.

$\S 2^{\circ}$ Deve ocorrer a tipagem $R h D$, observando os seguintes critérios:

I - o antígeno RhD deve ser determinado colocando-se as hemácias com antissoro anti-RhD (Anti-D);

II - em paralelo, deve ser sempre efetuado um controle da tipagem RhD, utilizando-se para isto soro-controle compatível com o antissoro utilizado (monoclonal ou policlonal) e do mesmo fabricante do anti-D;

III - se a reação for negativa para a presença do antígeno $R h D$, deve ser efetuada a pesquisa do antígeno $D$-fraco, considerando que: a) para a realização da 
pesquisa de antígeno $D$-fraco recomendase ser utilizado no mínimo dois antisoros anti-RhD (anti-D) contendo anticorpos da classe IgG obtidos de linhagens celulares distintas incluindo a fase da antiglobulina humana; b) quando a tipagem $R h D$ ou a pesquisa do antígeno $D$-fraco resultar positiva, o sangue deve ser rotulado como "RhD positivo"; c) quando ambas as provas resultarem negativas $O$ sangue deve ser rotulado como "RhD negativo"; d) em doadores de sangue tipados como $R h D$ negativo, recomenda-se a pesquisa dos antígenos $C$ (maiúsculo) e $E$ (maiúsculo) e os hemocomponentes devem ser devidamente identificados. A utilização dos concentrados de hemácias RhD negativo $C$ ou $E$ positivos deve obedecer a protocolos escritos específicos da instituição ou seguir critérios do responsável técnico de cada local; e e) se a reação com o sorocontrole de RhD for positiva, a tipagem $R h D$ é considerada inválida e o hemocomponente só deve ser rotulado e liberado para uso após a resolução do problema.

$\S 3^{\circ}$ Em relação às tipagens prévias de doações anteriores, deve-se observar que:

I - o registro de uma tipagem $A B O$ e $R h D$ prévia de um doador não serve para a identificação das unidades de sangue subseqüentemente doadas pelo mesmo doador;

II - novas determinações devem ser realizadas a cada doação;

III - em caso de doações prévias, deve ser comparada a tipagem $A B O$ e RhD com o último registro disponível; e

IV - qualquer discrepância deve ser resolvida antes de se rotular e liberar para uso os hemocomponentes produzidos.

$\S 4^{\circ}$ Deve ser realizada no sangue dos doadores a pesquisa de anticorpos antieritrocitários irregulares, empregando-se métodos que evidenciem a presença de anticorpos clinicamente significativos, observando os seguintes critérios:

I - os hemocomponentes que contenham anticorpos antieritrocitários irregulares devem ser rotulados como tais; $e$

II - as condições e situações nas quais estes componentes podem ser utilizados ficarão a critério do responsável técnico de cada local, sendo, porém 
recomendável que os componentes plasmáticos e os concentrados de plaquetas não sejam utilizados para transfusão.

\& 50 Recomenda-se ser realizado o teste de hemolisina para transfusões de plaquetas não isogrupo utilizando-se um método qualitativo com incubação a $37^{\circ} \mathrm{C}$. Hemocomponentes com resultados de hemólise total ou parcial devem ser evitados em transfusões não isogrupo.

A partir desta normativa, os serviços hemoterápicos produtores de hemocomponentes tiveram que adaptar sua rotina à implementação de técnicas para pesquisa de doadores com anticorpos de capacidade hemolítica, pesquisando este fator nas amostras de doadores com produção de hemocomponentes plaquetários. Embora a norma deixasse clara a não obrigatoriedade, os Hemocentros implementaram a pesquisa por se tratar de ensaio simples e sem custo adicional. Para tanto, tiveram que trabalhar com reagentes eritrocitários "frescos" preparados "in house" com matéria prima disponível em estoque, já que os comerciais disponíveis no mercado são compostos por soluções conservantes impossibilitando o ensaio pela não visualização da hemólise.

Neste momento, houve o despertar para a produção de reagentes eritrocitários para uso próprio, sem fins comerciais, razão pela qual este trabalho foi proposto.

Antunes et al. (2008) afirmam que é preciso garantir a terapêutica transfusional adequada ao paciente, assim, a realização do teste certo, com a amostra certa, para obter o resultado certo, assegura a transfusão do hemocomponente certo, para o doente certo, e previne a ocorrência de erros que são uma das principais causas de morbidade e mortalidade decorrentes da terapia sanguínea. Essas ações somente são obtidas em serviços que promovem ações preventivas na forma de tratamentos de ações não conformes e, também, de promoções permanentes de melhorias que garantam a qualidade de seus serviços. 


\section{Objetivos}




\section{OBJETIVOS}

\subsection{OBJETIVO GERAL}

Verificar a eficácia da produção de reagentes eritrocitários a partir de amostras de doadores de sangue;

\subsection{OBJETIVOS ESPECÍFICOS}

1. Validar o uso dos reagentes eritrocitários na rotina de investigação imunohematológica de doadores e receptores de transfusão;

2. Propor um protocolo de preparo de reagentes eritrocitários a partir de doações de sangue;

3. Determinar a correlação entre reagentes comerciais e reagentes produzidos a partir de amostras de doadores de sangue;

4. Determinar o perfil antigênico para produção de reagentes eritrocitários para prova reversa e triagem de anticorpos irregulares;

5. Demonstrar uma alternativa à não disponibilidade de reagentes eritrocitários comerciais. 


\section{Material e Métodos}




\section{MATERIAL E MÉTODOS}

\subsection{SELEÇÃO DAS MATÉRIA-PRIMA PARA A PRODUÇÃO DOS REAGENTES ERITOCITÁRIOS}

Este trabalho foi conduzido de acordo com a Resolução no 466 de 12 de dezembro de 2012, do Conselho Nacional de Saúde, utilizando o termo de consentimento informado para doadores de sangue padrão do Hemocentro de Ribeirão Preto (Anexo A). Este projeto teve como matéria prima uma amostra primária (tubo roxo colhido com anticoagulante EDTA) para rotina de ensaios imunohematológicos oriunda de doação de sangue total após seu processamento completo, envolvendo, para liberação dos hemocomponentes, as determinações:

a) Tipagem $A B O$ direta e reversa;

b) Pesquisa de anticorpos irregulares anti-eritrocitários;

c) Triagem para hemoglobina " $S$ " através do teste de solubilidade $e$

d) Pesquisa de hemolisina em doadores de bolsas triplas cujo cunho final é a produção de hemocomponentes plaquetários.

\subsection{PRODUÇÃO DOS REAGENTES ERITROCITÁRIOS E CONTROLES}

A partir da população de doadores de sangue do Hemocentro de Ribeirão Preto foram produzidos reagentes de triagem de anticorpos irregulares e de determinação $A B O$ pela prova reversa, os quais foram utilizados em paralelo aos kits comerciais na rotina pré-transfusional de receptores de transfusão.

Foram selecionados doadores com fenótipos específicos, sendo aliquotado um volume de aproximadamente $20 \mathrm{ml}$ de concentrado de hemácias da doação pertinente. Os concentrados de hemácia utilizados apresentavam até sete dias de coleta para garantir a viabilidade celular dos eritrócitos. A partir das alíquotas de hemácias, foram produzidos reagentes de triagem de anticorpos irregulares bem como reagentes para identificação de anticorpos antieritrocitários naturais, comumente conhecidos como prova reversa da determinação ABO. As alíquotas de 
hemácias foram lavadas com solução fisiológica e ressuspensas em solução conservante de eritrócitos CELL STAB, sendo essas soluções utilizadas por 30 dias.

\subsection{VALIDAÇÃO DOS REAGENTES ERITROCITÁRIOS}

Para a validação dos reagente eritrocitários foram selecionadas amostras teste de pacientes e realizados dois ensaios diferentes:

- Pesquisa de Anticorpos Irregulares (PAl);

- Tipagem confirmatória reversa para investigação de grupo sanguíneo ABO.

\section{3.1 Pesquisa de anticorpos irregulares (PAI) e tipagem confirmatória} reversa para investigação de grupo sanguíneo $A B O$.

A triagem/pesquisa de anticorpos eritrocitários (PAl) e a tipagem confirmatória reversa pra investigação de grupo sanguíneo $A B O$ foram realizadas em paralelo aos kits comerciais para amostras de soro/plasma e sangue total colhido em EDTA de receptores de transfusão provenientes do Hospital das Clínicas da Faculdade de Medicina de Ribeirão Preto, sala de transfusão do Hemocentro de Ribeirão Preto, Núcleos de Hemoterapia de Franca, Presidente Prudente, Araçatuba e Fernandópolis, todas as unidades vinculadas e dependentes diretamente do Hemocentro de Ribeirão Preto. Foram utilizadas amostras de pacientes aloimunizados e não aloimunizados para padronização da técnica e para controle dos reagentes.

No período de janeiro/2017 à junho/2017 foram produzidos 6 lotes de hemácias de triagem "in house" e testadas paralelamente às amostras de pacientes atendidos pelo complexo Hemocentro de Ribeirão Preto. Foram testadas 3358 amostras no total. 
Resultados 


\section{RESULTADOS}

No período de fevereiro/2003 à agosto/2005 instituiu-se um projeto piloto no qual foram preparados 16 lotes internos de células de triagem e testadas em paralelo com o kit comercial de triagem de anticorpos irregulares. Foram testadas 858 amostras de doadores de sangue por meio do uso dos 16 lotes de hemácias de triagem interna com validade de 30 dias cada lote. Neste período, dentro das reproduções em paralelo do lote comercial e do lote interno, obtivemos $95 \%$ de resultados iguais, $1 \%$ em que houve reação apenas no lote comercial e $4 \%$ com reação apenas no lote interno (Figura 4).

\section{RESULTADOS}

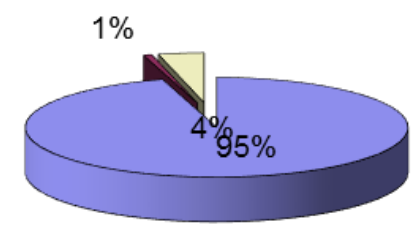

口resultados concordantes

口resultados disconcordantes reagiu apenas com hemácias comerciais

$\square$ resultados disconcordantes reagiu apenas com hemácias preparadas

Figura 4. Resultados comparativos dos 16 lotes iniciais de triagem de anticorpos. 
Após, a especificidade dos anticorpos evidenciados foi investigada:

Tabela 3. Identificação de anticorpos irregulares.

\begin{tabular}{cccccc}
\hline & Total & $\begin{array}{c}\text { Anticorpo } \\
\text { identificado }\end{array}$ & $\begin{array}{c}\text { Não } \\
\text { identificados }\end{array}$ & $\begin{array}{c}\text { Não } \\
\text { reagentes }\end{array}$ & Especificidade \\
\hline Kit & 858 & 3 & 2 & 1 & Anti-Jka (1) \\
Comercial & & 15 & 7 & 11 & Anti-Dia (2) \\
Kit Interno & 858 & & & Anti-Fya (1) \\
& & & & Anti-Kpa (2) \\
& & & & Anti-E (3) \\
& & & & Anti-C (1) \\
& & & Anti-e (2) \\
& & & Anti-Lua? (1) \\
& & & Anti-P (2) \\
& & & Anti-Fyb?(1) \\
\hline
\end{tabular}

No período de janeiro/2017 à junho/2017 foram produzidos 6 lotes de hemácias de triagem "in house" e testadas paralelamente às amostras de pacientes atendidos pelo complexo Hemocentro de Ribeirão Preto. Foram testadas 3358 amostras no total, que se apresentaram globalmente para o teste PAI como 3310 amostras concordantes e 48 amostras discordantes. (Figura 5).

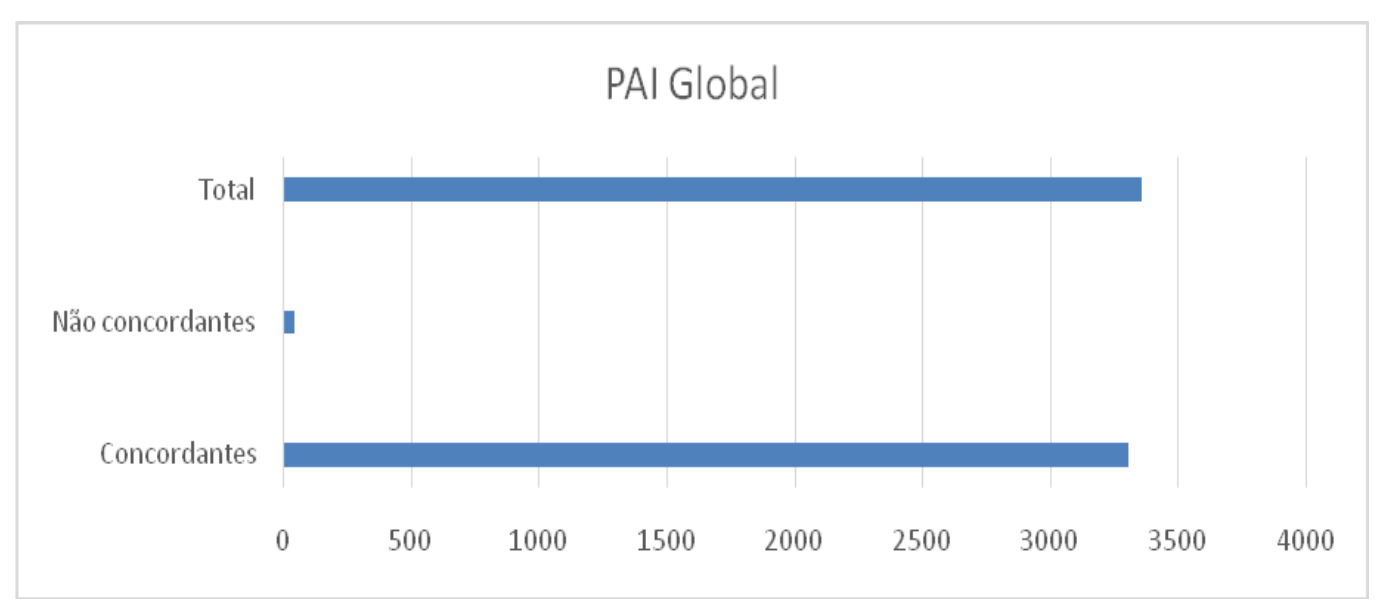

Figura 5. Resultado global para PAI testando hemácias comerciais e hemácias produzidas "in house". 
A identificação dos anticorpos irregulares realizada nas 16 amostras com resultados divergentes está representada na tabela 4.

Tabela 4. Resultados obtidos na identificação de anticorpos irregulares.

\begin{tabular}{lll}
\hline $\begin{array}{l}\text { Identificação do Anticorpo } \\
\text { Irregular }\end{array}$ & $\begin{array}{l}\text { Reagente Produção } \\
\text { Própria Hemocentro }\end{array}$ & Reagente Comercial \\
\hline Anti-E & $\begin{array}{l}3 \text { amostras com reatividade } \\
\text { de } 1+\end{array}$ & Não reagente \\
$\begin{array}{l}\text { Anticorpo não identificado } \\
\text { Anticorpo não identificado }\end{array}$ & & \\
\hline Anticorpo não identificado & $\begin{array}{l}9 \text { amostras com reatividade } \\
\text { fraca }\end{array}$ & Não reagente \\
\hline Anticorpo não identificado & $\begin{array}{l}1 \text { amostra com reatividade } \\
\text { de 3+ }\end{array}$ & Não reagente \\
\hline $\begin{array}{l}\text { Anticorpo não identificado } \\
\text { associado à auto anticorpo }\end{array}$ & Não reagente & $\begin{array}{l}1 \text { amostra com reatividade } \\
1+\end{array}$ \\
Anticorpo não identificado & Não reagente & $\begin{array}{l}2 \text { amostras com reatividade } \\
\text { fraca }\end{array}$ \\
\hline
\end{tabular}

Fonte: Autoria própria. 
Discussão 


\section{DISCUSSÃO}

A rotina pré-transfusional demanda testes preliminares para a segurança do paciente, transfusões incompatíveis podem acarretar óbito. Neste sentido, a legislação vigente em hemoterapia - Portaria de Consolidação número 5 do Ministério da Saúde - prevê obrigatoriedade de exames antes do ato transfusional. Exames qualificatórios que incluem desde a testagem das amostras de doadores no início da cadeia até a retestagem do hemocomponente eritrocitário do doador frente à amostra do receptor por meio de exames laboratoriais imuno-hematológicos de baixo custo operacional, porém, de extrema importância para que a transfusão seja bem-sucedida.

O foco deste estudo foram os reagentes eritrocitários utilizados nos exames de qualificação imuno-hematológicos abrangendo amostras de doadores e receptores sanguíneos. Em relação à legislação vigente em hemoterapia, as figuras 6 e 7 ilustram os exames que utilizam reagentes eritrocitários.

Art. 118. $A$ tipagem $A B O$ será realizada testando-se as hemácias com reagentes anti- $A$, anti- $B$ e anti- $A B$, sendo que no caso de serem usados antissoros monoclonais, a utilização do soro anti-AB não é obrigatória. (Origem: PRT MS/GM 158/2016, Art. 119)

$\S 1^{\circ} \mathrm{A}$ tipagem reversa deve ser sempre realizada, testando-se o soro ou plasma de amostra da doação com suspensões de hemácias conhecidas A1 e B e, opcionalmente, A2 e O. (Origem: PRT MS/GM 158/2016, Art. 119, § $1^{\circ}$ )

$\S 2^{\circ}$ Nenhum componente sanguineo será rotulado e liberado para utilização até que qualquer discrepância entre a tipagem direta e reversa tenha sido resolvida. (Origem: PRT MS/GM 158/2016, Art. 119, § $2^{\circ}$ )

Figura 6. Portaria de Consolidação Número 5 - Ministério da Saúde. Exames qualificatórios em doadores de sangue. Seção VI Dos Exames de Qualificação no Sangue do Doador (Origem: PRT MS/GM 158/2016, TíTULO II, CAPÍTULO I, Seção VI). 
Art. 176. Os testes pré-transfusionais incluirão: (Origem: PRT MS/GM 158/2016, Art. 177)

I - para sangue total e concentrado de hemácias: (Origem: PRT MS/GM 158/2016, Art. 177, I)

a) a tipagem $A B O$ (direta e reversa) e RhD e a pesquisa de anticorpos antieritrocitários irregulares no sangue do receptor; (Origem: PRT MS/GM 158/2016, Art. 177, I, a)

Art. 177. Nos exames de sangue do receptor, a tipagem $A B O$ e $\mathrm{RhD}$ e a pesquisa de anticorpos antieritrocitários irregulares serão realizadas nas amostras de sangue do receptor de componentes eritrocitários. (Origem: PRT MS/GM 158/2016, Art. 178)

Figura 7. Portaria de Consolidação Número 5 - Ministério da Saúde. Seção X Da Transfusão Sanguínea (Origem: PRT MS/GM 158/2016, TíTULO II, CAPÍTULO I, Seção X).

Sob orientação da legislação vigente e visando melhor qualidade dos reagentes eritrocitários, maior aprimoramento dos profissionais de banco de sangue e objetivando a diminuição de custos com reagentes comerciais, foram testadas 3358 amostras de receptores de transfusão para Pesquisa de Anticorpos Irregulares (PAI) nas unidades pertencentes ao Complexo Hemocentro de Ribeirão Preto. Entre as 3358 amostras testadas, 48 apresentaram resultados discordantes quando comparado o uso do reagente comercial de triagem com o uso do reagente de produção própria na mesma metodologia, a técnica em tubo.

A Fundação Hemocentro de Ribeirão Preto (FUNDHERP) foi criada em 1990 para administrar toda a rede de atendimento do Centro Regional de Hemoterapia que é um departamento do Hospital das Clínicas da Faculdade de Medicina de Ribeirão Preto, Universidade de São Paulo. Está localizado na região nordeste do estado de São Paulo, com uma rede composta por diversos serviços de hemoterapia de diferentes complexidades, que atende uma região com uma população de cerca de cinco milhões de habitantes.

As 3358 amostras utilizadas neste estudo foram regionalmente analisadas, nas próprias unidades externas vinculadas ao Hemocentro de Ribeirão Preto:

1. Agência Transfusional do Hospital das Clínicas da Faculdade de Medicina de Ribeirão Preto; 
2. Núcleo de Hemoterapia de Araçatuba;

3. Núcleo de Hemoterapia de Fernandópolis;

4. Núcleo de Hemoterapia de Presidente Prudente;

5. Núcleo de Hemoterapia de Franca e

6. Hemocentro sede.

Na Agência Transfusional do Hospital das Clínicas de Ribeirão Preto, foram testadas 2058 amostras de pacientes para PAI. Do total de amostras, 16 foram discordantes em relação aos resultados obtidos com os reagentes eritrocitários comerciais e de produção própria. Entre as 16 amostras discordantes, 12 diferiram no grau de aglutinação em tubo, mas com interpretação final coerente entre os dois $k i t s$ de reagentes utilizados. As outras 4 amostras, tiveram resultados finais diferentes com os reagentes comerciais e os de produção própria.

Para a prova reversa na confirmação da tipagem $A B O$, a Agência Transfusional do Hospital das Clínicas testou 2542 amostras e obteve resultado concordante em 2529 amostras que reproduziram os testes em mesma intensidade de aglutinação. 13 amostras foram discordantes em intensidade de aglutinação, apresentando diferenças sutis de 1+ no resultado de leitura entre elas, mas com interpretação final condizente para interpretação $A B O$ quando comparados os reagentes comerciais e de produção própria.

Nos Núcleos de Hemoterapia externos, não houveram discordâncias entre os resultados dos reagentes comercias em paralelo aos de produção própria, os resultados foram os mesmos na interpretação da intensidade de aglutinação em tubo e na interpretação final do teste. O Núcleo de Araçatuba executou 90 testes com amostras de pacientes candidatos à transfusão sanguínea, o Núcleo de Fernandópolis foi responsável pela testagem de 353 amostras de candidatos à transfusão de sangue e o Núcleo de Presidente Prudente testou 454 amostras de pacientes com pedido de exame pré-transfusional.

As unidades externas acima mencionadas realizaram os ensaios por meio de três lotes diferentes de reagentes de produção própria para PAI e executaram os testes nos meses de abril à junho de 2017.

Para a prova reversa, apenas o Núcleo de Presidente Prudente avaliou em paralelo reagente comercial e de produção própria em 529 amostras que mostram resultado final concordante para interpretação do ensaio e 
divergente apenas em intensidade de reação em 64 delas com variação de 1+ entre elas.

O Núcleo de Hemoterapia de Franca avaliou apenas a prova reversa em 131 amostras de pacientes, obtendo 123 amostras concordantes para a intensidade de aglutinação e apenas 8 amostras com diferenças de 1+ na intensidade quando comparados os reagentes eritrocitários para prova reversa e produção interna, não afetando o resultado de interpretação final.

O Hemocentro sede, pioneiro nos testes comparativos entre reagentes comerciais e de produção própria para triagem de anticorpos irregulares, iniciou a pesquisa no mês de janeiro de 2017 e concluiu em março de 2017. Foram testadas neste período 387 amostras de candidatos à transfusão, obtendo resultados concordantes em 355 delas e discordantes em 32 amostras. Dentro das amostras discordantes, 16 foram relacionadas a intensidade da reação de aglutinação observada na técnica em tubo, o que não impactou a interpretação final do resultado para ambos reagentes, porém, 16 amostras tiveram seus resultados finais divergentes.

Dentre as 16 amostras com interpretação final divergente, observou-se que 13 amostras apresentaram reatividade quando utilizado o reagente de produção própria frente aos comercial e três amostras foram reativas apenas no reagente comercial.

O Hemocentro sede continuou a investigação das 16 amostras com resultados divergentes quanto ao parecer final do exame, por ser detentor de técnicas de identificação de anticorpos mais sensíveis em relação às unidades externas. Em treze amostras não foi possível identificar o anticorpo e nas outras três foi observado o Anti-E (Tabela 4).

\begin{tabular}{l|l|l}
\hline $\begin{array}{l}\text { Identificação do Anticorpo } \\
\text { Irregular }\end{array}$ & $\begin{array}{l}\text { Reagente Produção } \\
\text { Própria Hemocentro }\end{array}$ & Reagente Comercial \\
\hline Anti-E & $\begin{array}{l}\text { 3 amostras com } \\
\text { reatividade de 1+ }\end{array}$ & Não reagente \\
$\begin{array}{l}\text { Anticorpo não identificado } \\
\text { Anticorpo não identificado }\end{array}$ & $\begin{array}{l}\text { 9 amostras com } \\
\text { reatividade fraca }\end{array}$ & Não reagente \\
\hline Anticorpo não identificado & 1 amostra com reatividade & Não reagente \\
\hline Anticorpo não identificado & & \\
\hline
\end{tabular}




\begin{tabular}{l|l|l}
\hline & de 3+ & \\
\hline $\begin{array}{l}\text { Anticorpo não identificado } \\
\text { associado à auto } \\
\text { anticorpo }\end{array}$ & Não reagente & $\begin{array}{l}1 \text { amostra com reatividade } \\
1+\end{array}$ \\
\hline Anticorpo não identificado & Não reagente & $\begin{array}{l}2 \text { amostras com } \\
\text { reatividade fraca }\end{array}$ \\
\hline
\end{tabular}

Para a prova reversa $A B O$, no Hemocentro cede foram testadas 153 amostras, e obtivemos um resultado igual em intensidade de aglutinação e interpretação final em 131 delas, por outro lado houveram 22 amostras concordantes na interpretação final, mas com diferença de intensidade variando 1+ entre os reagentes de produção interna e comercial.

Diante do exposto algumas considerações devem ser colocadas:

- A metodologia em tubo aplicada aos testes imuno-hematológicos embora de baixo custo gera subjetividade e insegurança na interpretação dos resultados, evidência observada tanto no uso de reagentes eritrocitários comerciais quanto nos de produção própria;

- Não existem kits de reagentes eritrocitários capazes de detectar $100 \%$ dos anticorpos irregulares na rotina imunohematológica;

- Houve uma maior sensibilidade na detecção de anticorpos irregulares quando utilizados reagentes eritrocitários de produção própria frente aos comerciais, embora o resultado final de especificidade não tenha sido satisfatório para este estudo;

- Os Hemocentros são detentores de matéria prima e know-how para produção de reagentes eritrocitários próprios objetivando a redução de custos e a personalização regional por população atendida. 
Conclui-se portanto, que a produção de reagentes eritrocitários pelos serviços de Hemoterapia de grande porte é factível independente da metodologia utilizada para os testes pré-transfusionais, e, em relação à custos, a economia gerada pela produção interna de reagentes eritrocitários poderia ser revertida à implementação de metodologia mais sensíveis que a técnica subjetiva em tudo associada à oportunidade de ampliar os recursos técnicos com aquisição de outros reagentes para a rotina pré-transfusional que melhore sua qualidade de capacidade de resolução de casos complexos. 
Referências Bibliográficas 


\section{REFERÊNCIAS BIBLIOGRÁFICAS}

AMERICAN ASSOCIATION OF BLOOD BANKS. Technical Manual. 12 $2^{\mathrm{a}}$ ed. Bethesda: AABB, 1996; 13ª ed. Bethesda, Maryland: AABB, 1999 e 2000.

CALLEGARI-JACQUES, S. M. et al. Futher blood genetic studies on Amazonian diversity: data from Indian groups. Annals of Human Biology, v.21, p. 465-481, 1994.

GIRELLO, ANA LÚCIA, Fundamentos da Imuno-hematologia eritrocitária / Ana Lúcia Girello, Telma Ingrid Borges de Bellis Kuhn. - São Paulo: Editora SENAC São Paulo, 2002.

HARMENING, D. Modern Blood Banking Transfusion Pratices. Filadélfia: F. A. Davis Company, 1989.

KLEIN, H. G. ; ANSTEE, D. J. Mollison's Blood transfusion in clinical medicine. $11^{\underline{a}}$ ed. Malden, Massachusets: Blackwell Publishing, 2005.

OLIVEIRA, M. C. V. et al. Frequencia dos grupos sanguíneos em doadores de sangue no Brasil. Boletim Soc. Bras. Hematol. Hemot., São Paulo, v. 18, 1996. Suplemento.

WESTHOFF, C. M., REID, M. E. ABO and Related Antigens and Antibodies. In: HILLEYR, C. D. et al. Blood Banking and Transfusion Medicine: basic principles and pratice. $2^{\text {nd }}$ ed. Philadelphia, USA: Churchill Livingstone Elsevier, 2007. p. 69-79.

Rh, Kell, Duffy, and Kidd Antigens and Antibodies. In: HILLYER, C. D. et al. Blood Banking and Transfusion Medicine: basic principles and pratice. $2^{\text {nd }}$ ed. Philadelphia, USA: Churchill Livingstone Elsevier, 2007. p. 80-95. 
Anexos 


\title{
ANEXO A - Termo de consentimento informado para doadores de sangue padrão Hemocentro de Ribeirão Preto.
}

\section{TERMO DE CONSENTIMENTO INFORMADO PARA DOADORES DE SANGUE}

\begin{abstract}
Triagem:
1. O (A) Sr.(a) recebeu as orientaçōes sobre doação de sangue, verbais e escritas no impresso FH 2.67 Rev (Orientaçôes Preliminares ao Doador de Sangue).

2. O (A) Sr.(a) tomou conhecimento dos procedimentos necessários para fazer a doaçẫo e autoriza a retirada de 400 a $500 \mathrm{ml}$ (aproximadamente meio litro, o que representa $10 \%$ da quantidade de sangue que possui). A coleta do sangue será realizada através da introdução de uma agulha numa veia superficial do braço.
\end{abstract}

3. O (A) Sr.(a) tomou conhecimento que riscos relacionados à doaçăo săo muito baixos, mas pode ocorrer formaçăo de hematoma no local da punçăo, queda de pressấo arterial, tontura, dentre outros.

4. Foi informado de que existem doenças como hepatite e AIDS, que podem ser transmitidas de uma pessoa para outra por transfusấo de sangue, mesmo que o doador esteja se sentindo bem e tenha seus exames negativos. Isto acontece porque os exames não detectam estas doenças por um periodo logo após a pessoa adquiri-las. Por isso, caso seu objetivo seja apenas fazer exames, é melhor nâo doar sangue e solicitar esclarecimentos ao triador, pois, do contrário, você pode estar colocando a vida de outras pessoas em risco.

5. O sangue doado destina-se essencialmente à transfusâo de pacientes, e a segurança deles depende muito da sua sinceridade na entrevista.

6. Foi informado de que serão feitos exames obrigatórios no sangue doado e que poderá ser necessária a realização de outros exames complementares. Além disso, algumas situaçōes (soro gorduroso) poderâo impedir a realizaçăo de um ou mais dos exames previstos. Uma amostra do seu sangue será armazenada por pelo menos 6 meses, conforme obriga a legislaçăo.

7. Caso algum de seus exames tenha resultado alterado, o (a) $\mathrm{Sr}$ (a) será chamado por este serviço ou pelo órgâo de vigilância em saúde com o objetivo de orientar e confirmar resultados, pois um exame alterado năo significa que o (a) Sr.(a) esteja necessariamente doente. Nessa oportunidade poderá ser encaminhado, se necessário, para outro serviço especializado.

FH-2.46 (REV. 06)

8. Informamos que o excedente do sangue doado poderá ser usado para produção de hemoderivados e insumos (produtos utilizados para exames). Caso seu sangue nāo seja considerado adequado para uso, ele será descartado.

9. Autorizo que meu nome seja incorporado a um arquivo de doadores potenciais, local e nacional, e concordo em ser convidado a doar sempre que precisarem de mim.

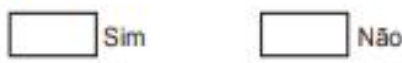

10. Autorizo que amostra de meu sangue constitua o banco de amostras biológicas com potencial uso em pesquisa futura. Eventual pesquisa com meu sangue somente será realizada após aprovação do Comitê de Ética em Pesquisa. Além disso, estou ciente de que posso ser contatado para manifestar meu consentimento e/ou receber esclarecimentos. Sei que em qualquer circunstância meu sigilo e minha privacidade serăo preservados. Sei ainda que a năo concordância do uso da amostra em pesquisa não impedirá o uso transfusional do sangue doado.

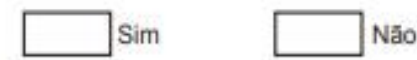

Diante das informaçōes recebidas, declaro que entendi e respondi com a verdade todas as perguntas da entrevista e tive a oportunidade de esclarecer eventuais dúvidas.

Concordo com a realizaçâo de todos os procedimentos descritos e autorizo a retirada do meu sangue.

Autorizo ainda que os resultados alterados sejam informados à autoridade sanitária conforme norma sanitária.

de de 20

Nome: 